\title{
La imputación del pago en el Código Civil
}

\section{Luciano Barchi Velaochaga}

\section{Introducción}

En el hipotético caso de que un deudor realizara un pago que no alcanzara para cubrir varias obligaciones con la misma naturaleza (fungible y homogénea), se generaría cierta incertidumbre. Como señala Breccia (1991), el problema nace cuando la posibilidad de equívoco exista, como puede suceder si hay varias prestaciones del mismo monto y la suma ofrecida en pago sea insuficiente para extinguir solo una, o bien si todas las prestaciones son de diverso monto y la suma ofrecida solo pueda comprender una parte que no sea posible de determinar de alguna manera (p. 565).

Como es de conocimiento general, imputar significa señalar la aplicación de un desplazamiento patrimonial (pago) a una determinada obligación entre una pluralidad de obligaciones de la misma naturaleza constituidas por prestaciones fungibles y homogéneas entre un mismo deudor y un mismo acreedor. Así, por ejemplo, si el deudor tiene con el acreedor dos obligaciones pecuniarias por $\mathrm{S} / 120,00$ y ejecuta un pago de $S / 120,00$, debe establecerse si este pago debe ser imputado a la primera o a la segunda obligación. El problema, precisamente, encuentra solución en la disciplina de la imputación del pago. 
Por otro lado, Bianca (1993) define la imputación como "un nexo entre prestación y relación obligatoria que puede tener como fuente un acto de parte o la ley" (p. 335). Quizá sería más preciso decir que la imputación es el nexo que vincula un desplazamiento patrimonial (pago) con una relación obligatoria. Como se verá más adelante, en razón de su fuente, la imputación se distingue en voluntaria (derivada de una manifestación de voluntad de una de las partes) o legal.

\section{Presupuestos de la imputación}

En el caso peruano, el artículo 1256 del Código Civil (1984) establece los presupuestos de la imputación: "Quien tiene varias obligaciones de la misma naturaleza constituidas por prestaciones fungibles y homogéneas, a favor de un solo acreedor".

\subsection{Primer presupuesto: la existencia de pluralidad de relaciones obligatorias (ex pluribus causis) que vinculen al mismo acreedor y al mismo deudor}

Como señala Hernández (1988), lo normal será que las deudas procedan de relaciones obligatorias diferentes, pero también pueden proceder de una sola relación obligatoria como, por ejemplo, cuando en razón de un contrato de arrendamiento se deben rentas correspondientes a diferentes períodos de tiempo (p. 313).

Por lo que se refiere a este punto, Díez-Picazo (1996) comenta la discusión respecto a si las diferentes relaciones obligatorias deben o no ser autónomas e independientes. Quienes responden afirmativamente se sustentan en lo mencionado en el parágrafo 366 del German Civil Code (BGB): “(1) Si el deudor está obligado frente al acreedor a prestaciones del mismo tipo derivadas de diversas relaciones obligatorias [cursivas añadidas] [...]" (p. 524).

De acuerdo con el autor español:

Este problema guarda relación con la cuestión relativa a si las reglas de imputación pueden funcionar en relación con porciones diferentes y de algún modo separadas de una misma deuda. El artículo 1173, al aludir a la imputación entre principal e intereses, parece adoptar respecto de ello una solución afirmativa. (Díez-Picazo, 1996, p. 525) 
Por su parte, Breccia (1991), en Italia, señala:

La pluralidad de las deudas (a las cuales se refiere el primer párrafo del artículo $1193,1^{10}$ ) puede ser interpretada en sentido amplio, con referencia a la hipótesis en la cual la obligación sea única pero subdividida en una serie de prestaciones parciales que el acreedor no pueda rehusarse a recibir en razón del título o de una pertinente previsión legal [piénsese en los pagos "en cuotas" a las rentas de un arrendamiento, a las prestaciones periódicas de un suministro, a las rentas de un rendimiento]. (p. 331)

Bianca (1993) indica que, si el acreedor no rehúsa el pago parcial [artículo 1221 del Código Civil], el deudor puede ejercer su facultad de imputación también en el ámbito de la única deuda. Así, por ejemplo, en el caso de que el deudor tenga una deuda de 150 millones garantizada por una fianza hasta por el importe de 100 millones, la prestación realizada de 100 millones podrá ser imputada a la parte de la deuda garantizada, extinguiendo la fianza (p. 339).

Conforme a ello, la jurisprudencia italiana se ha mostrado a favor de la tesis según la cual la disciplina de la imputación del pago -si bien presupone la existencia de una pluralidad de relaciones obligatorias con prestaciones fungibles y homogéneas entre las mismas partespuede ser aplicable analógicamente en presencia de una pluralidad de acreedores, si sucediera que uno de ellos sea legitimado a recibir el pago por cuenta propia y por cuenta ajena. Así, en un caso, un mismo sujeto recibió un pago siendo acreedor del deudor y siendo representante legal de una sociedad que, a su vez, también era acreedora del deudor (Bordon, 2009, p. 312).

Normas sobre imputación del pago se encuentran en los Principios sobre los Contratos Comerciales Internacionales (UNIDROIT) (2010). Así el artículo 6.1.12 señala: "(1) Un deudor de varias obligaciones [cursivas añadidas] dinerarias al mismo acreedor [...]". También se hallan en los Principios de Derecho Europeo de los Contratos, donde el artículo 7:109 expresa: “(1) Quando il debitore debe adempiere più obbligazioni [cursivas añadidas] [...]". Ambos principios se refieren a la necesidad de "varias obligaciones" (UNIDROIT, 2010).

1 "Quien tiene una pluralidad de deudas de la misma especie frente a la misma persona puede declarar, cuando paga, qué deuda entiende satisfacer [...]". 
Si bien el artículo 1256 del Código Civil peruano (1984) hace referencia a una pluralidad de obligaciones: "Quien tiene varias obligaciones [cursivas añadidas] [...]", en otros pasajes parece admitir la tesis según la cual la disciplina de la imputación del pago resulta de aplicación también a la hipótesis en la cual la obligación sea única, pero subdividida en una serie de prestaciones parciales. En efecto, en su artículo 1231 establece: “Cuando el pago deba efectuarse en cuotas periódicas, el recibo de alguna o de la última, en su caso, hace presumir el pago de las anteriores, salvo prueba en contrario". El artículo citado se refiere al caso en el que el pago deba efectuarse en "cuotas periódicas"; no obstante, debe distinguirse entre "prestación fraccionada" y "prestaciones periódicas".

La prestación fraccionada es una prestación única cuya naturaleza permite su división y la voluntad de las partes fracciona la prestación en porciones, armadas o cuotas. En tal sentido, se tiene una pluralidad de "cuotas" en el tiempo (cuotas periódicas). Por ejemplo, el pago del precio de una compraventa a plazos.

Las prestaciones periódicas se dan en aquellos casos en que el proyecto de las partes prevé una serie de actos del deudor, de idéntica naturaleza y de contenido homogéneo, pero separados por períodos determinados de tiempo. Las prestaciones periódicas, desde el punto de vista de su estructuración, se conciben como varias prestaciones sucesivas e independientes distanciadas temporalmente. A manera de ejemplo, el pago de la renta en el arrendamiento.

El artículo 1231 del Código Civil (1984) establece las "cuotas periódicas", y ello podría inducir a pensar que solo comprende casos de prestación fraccionada. Del mismo modo, por ejemplo, el artículo 1323 del Código Civil ${ }^{2}$ también se refiere a "cuotas periódicas", pero comprende únicamente el caso de prestación fraccionada, no el de las prestaciones periódicas. No obstante, el artículo 1231 del Código Civil comprende el caso de prestación fraccionada y también el caso de prestaciones recíprocas.

En una opinión distinta, que parece restringir el artículo 1231 a las prestaciones periódicas y no comprender la prestación fraccionada,

2 "Cuando el pago deba efectuarse en cuotas periódicas [cursivas añadidas], el incumplimiento de tres cuotas, sucesivas o no, concede al acreedor el derecho de exigir al deudor el inmediato pago del saldo, dándose por vencidas las cuotas que estuviesen pendientes, salvo pacto en contrario". 
Osterling y Castillo (1996) sostienen: “El artículo 1231 del Código Civil peruano hace referencia al pago de obligaciones cuyas prestaciones sean de ejecución periódica, en la modalidad periódica propiamente dicha, así como en la modalidad continuada o continua" (p. 451).

En Argentina, Cazeaux y Trigo (1986), comentando el artículo 746 del Código Civil argentino, en cambio, solo lo restringen al caso de prestación fraccionada cuando señalan:

De su propio contexto resulta, pues, que esta disposición se refiere a obligaciones cuyo objeto está fraccionado en prestaciones parciales o cuotas, como sucede verbigracia en una compraventa por mensualidades... [De acuerdo con dichos autores, lo usual es que] los acreedores no suelen dar recibo por un período cuando se les adeuda el anterior. (p. 213)

La presunción del artículo 1231 del Código Civil (1984) se basa en el hecho de que si, por ejemplo, el deudor debe las "cuotas" 3, 4 y 5, al momento de efectuarse el pago de una cuota el acreedor no daría por pagada la cuota 5 antes que la 3; es decir, imputaría el pago a la más antigua.

\subsection{Segundo presupuesto: que la pluralidad se refiera a deudas de la misma especie}

Debe tratarse de obligaciones cuyas prestaciones tengan el mismo objeto, de modo que, abstractamente, el pago pueda referirse indiferentemente a cualquiera de ellas. Debe tratarse, entonces, de prestaciones fungibles ${ }^{3}$ y homogéneas ${ }^{4}$.

Las obligaciones dinerarias representan naturalmente la inmensa mayoría; en este sentido, el artículo 6.1.12 de los Principios sobre los Contratos Comerciales Internacionales (UNIDROIT) (2010) señala: “(1) Un deudor de varias obligaciones dinerarias [cursivas añadidas] al mismo acreedor [...]". No obstante, el artículo 6.1.13 se refiere a la imputación del pago de obligaciones no dinerarias: "El artículo 6.1.12 se aplica, con las adaptaciones del caso, a la imputación del pago de obligaciones no dinerarias" (UNIDROIT, 2010).

3 Cabe señalar que fungibilidad significa la sustituibilidad, es decir, la aptitud de las cosas para ser recíprocamente sustituidas unas por otras.

4 Es decir, que sea indiferente el pagar una u otra. Por ejemplo, el arroz y el azúcar son cosas fungibles, pero no homogéneas. 
En los comentarios al artículo 6.1.13, se dice:

El problema de imputación del pago suele vincularse con el pago de obligaciones dinerarias, pero pueden presentarse dificultades semejantes con obligaciones de otra naturaleza. El art. 6.1.13 expresa que las reglas sobre imputación del pago aplicables a las obligaciones dinerarias se aplicarán, con las modificaciones pertinentes, a las obligaciones no dinerarias. (UNIDROIT, 2010)

De igual manera, se propone el siguiente ejemplo:

"A" debe construir obras en diversas localidades de un país africano. Para cumplir con su trabajo, celebra con "B" cinco contratos separados y sucesivos, en virtud de los cuales " $\mathrm{B}$ " se obliga a entregarle a " $\mathrm{A}$ " diversas cantidades de cemento de Amberes, en la misma fecha y transportadas en el mismo barco. Los cinco contratos son similares, con excepción del tercero y quinto contrato, que incluyen cláusulas penales de monto muy alto para el caso de demora en la entrega de cemento. Debido a ciertas complicaciones, "B" sólo puede entregar parte del cemento. En el momento de la entrega, "B" puede indicar que el cemento entregado deberá imputarse en pago del tercero y quinto contrato. (UNIDROIT, 2010, p. 136)

Para Natoli, no solo deben ser homogéneas cualitativamente, sino también cuantitativamente; puesto que si fueran de sumas distintas (una menor y otra mayor), no habría incertidumbre respecto a la suma pagada, teniendo en cuenta que el acreedor siempre podrá rehusar el pago parcial (Bordon, 2009, pp. 301). En efecto, si, por ejemplo, el deudor tiene con el acreedor dos obligaciones pecuniarias: una por S/ 120,00 y la otra por S/ 100,00 y ejecuta un pago de S/ 100,00, no habría incertidumbre respecto a qué obligación se refiere el pago, puesto que se requeriría el consentimiento del acreedor para imputar el pago parcialmente a la deuda mayor.

La imputación queda excluida cuando las prestaciones versan sobre cosas específicas; en ese sentido, al comentar el nuevo artículo 1864 del Louisiana Civil Code, que reemplaza la expresión imputation of performance del artículo 2163 del Civil Code del año 1870 por la expresión imputation of payment se dice: "Payments is this confined to mean the performance of an obligation to pay money or to give fungible things" 5 .

5 El término pago está confinado a significar el cumplimiento de una obligación dineraria o de dar cosas fungibles. 
Osterling y Castillo (1996) tienen una opinión distinta. De acuerdo con los autores nacionales, "la imputación del pago puede estar referida a bienes inciertos (determinables)"; ponen el siguiente ejemplo:

Si un deudor hubiese contraído con su acreedor dos obligaciones distintas de entregar un cuadro y se practicara la elección sin especificarse a cual obligación se refiere; al ejecutarse la prestación, tendrían que aplicarse las reglas de la imputación del pago. (Osterling y Castillo, 1996, p. 320)

Más adelante, señalan que "el tema de la imputación del pago, aunque aisladamente, también podría presentarse en las obligaciones de hacer" (Osterling y Castillo, 1996), y colocan el siguiente ejemplo:

Si una empresa de limpieza [...] contrajese dos obligaciones distintas con el dueño de un edificio, consistente cada una de ellas en limpiar una vez al año las ventanas del referido inmueble, y sólo lo hiciese una vez, ¿podría entenderse que esté ejecutando la primera obligación contraída? ¿O se entendería que no puede conocerse con exactitud cuál de las dos está cumpliendo, ya que ambas consisten exactamente en lo mismo, y no se ha especificado, al contraerlas, las fechas en que deben ejecutarse? Nos inclinamos, en este caso, a considerar que tendrían que aplicarse las reglas de imputación del pago, pues ambas prestaciones son de la misma naturaleza y homogéneas entre sí. (Osterling y Castillo, 1996, p. 321)

Finalmente, respecto a las relaciones obligatorias con prestación de no hacer, expresan que "en esta clase de obligaciones no se aplican los principios de la imputación del pago" (Osterling y Castillo, 1996, p. 321).

\section{Clases de imputación}

Como se ha señalado, la imputación es el nexo que vincula un desplazamiento patrimonial (pago) con una relación obligatoria y puede tener su fuente en una manifestación de voluntad de una de las partes (imputación voluntaria) o en la ley (imputación legal). En tal sentido, en razón de su fuente, la imputación puede ser voluntaria o legal (Pothier, 2007, p. 333). 


\subsection{Imputación voluntaria}

La imputación voluntaria es aquella que tiene fuente en la manifestación de voluntad de una de las partes de la relación obligatoria. En tal sentido, la imputación voluntaria puede ser imputación voluntaria por manifestación de voluntad del deudor (imputación por el deudor) o imputación voluntaria por manifestación de voluntad del acreedor (imputación por el acreedor).

La imputación voluntaria es la manifestación de voluntad del deudor o del acreedor mediante la cual determinan la relación obligatoria a la que es referida la atribución patrimonial (pago) efectuada por el deudor. En tal sentido, como se verá, la imputación se perfecciona con la sola manifestación de voluntad del declarante (deudor o acreedor) dirigida a la otra parte; es decir, se trata de un acto jurídico unilateral y recepticio.

Gomes (1986), en Brasil, indica que la imputación puede resultar del acuerdo entre los interesados o, a falta de este, por la prescripción legal. La imputación por acuerdo supone que las disposiciones legales sobre imputación tienen carácter supletorio. Si no hay acuerdo, la ley prescribe que corresponde al deudor la imputación (p. 127).

El artículo 1475 del Código Civil uruguayo (1995) señala:

La imputación es convencional cuando se estipula por el deudor en el acto de pago, o se indica por el acreedor en el recibo que diese el deudor.

Es legal, cuando se hace por la ley, a falta de la que el deudor y acreedor habrían podido hacer.

Si bien el texto transcrito trata de "imputación convencional", parece aludir a la naturaleza contractual de la imputación. En realidad, al definir se refiere a un acto unilateral. Al respecto, Bianca (1993) señala que el eventual acuerdo de las partes no excluye la sustancial unilateralidad del acto. Para el autor italiano, el acuerdo se hace necesario cuando falten los requisitos o sean superados los límites previstos por la ley para la imputación voluntaria (pp. 337-338). 


\subsubsection{Imputación por el deudor}

\section{a. Naturaleza de la imputación por el deudor}

La imputación del pago corresponde, en primer lugar, al deudor ${ }^{6}$. De acuerdo con Díez-Picazo (1996), esta regla se funda en el criterio del favor debitoris (p. 524).

Conforme con el artículo 1256 del Código Civil (1984), el deudor de una pluralidad de obligaciones (con "prestaciones fungibles y homogéneas") frente a un mismo acreedor tiene el derecho potestativo de declarar/elegir, "al tiempo de hacer el pago, o, en todo caso, antes de aceptar el recibo emitido por el acreedor" a cuál de ellas se aplica el pago:

Quien tiene varias obligaciones [cursivas añadidas] de la misma naturaleza constituidas por prestaciones fungibles y homogéneas, a favor de un solo acreedor, puede indicar [cursivas añadidas] al tiempo de hacer el pago, o, en todo caso, antes de aceptar el recibo emitido por el acreedor, a cuál de ellas se aplica éste.

El derecho de imputar constituye un derecho potestativo del deudor. A un derecho potestativo (situación de ventaja) se le opone una situación de sujeción (situación de desventaja). Como exponen Caringella y De Marzo (2008):

En los derechos potestativos el titular está premunido del poder de actuar unilateralmente y modificar la esfera jurídica del sujeto pasivo que, de su parte, no debe hacer nada para consentir que el titular del derecho consiga su interés, y no puede hacer nada para impedir que lo consiga. Este se encuentra, en efecto, en una situación de sujeción. (p. 21)

En tal sentido, ejercido el derecho de imputar por el deudor, el acreedor debe sujetarse a su decisión siempre que se efectúe dentro de los límites establecidos en el segundo párrafo del artículo 1256 y el artículo 1257 del Código Civil (1984).

La declaración con la cual se imputa el pago es unilateral y recepticia (Caringella y De Marzo, 2008). No requiere de una forma determinada. No se excluye que la declaración de voluntad sea tácita, siempre que la

6 El artículo 1253 del Código Civil francés (1804) señala: "Le débiteur de plusieurs dettes a le droit de déclarer, lorsqu'll paye, quelle dette il entend acquitter". 
imputación se deduzca de elementos claros y unívocos, que estén en condiciones de eliminar la situación de incertidumbre del pago (p. 571).

De acuerdo con Bozzi (2009), la voluntad de la imputación puede ser tácita o resultar de hechos concluyentes (facta concludentia); en cambio, su determinación puede ocurrir mediante presunciones, como en el caso de que el monto de la prestación pagada corresponda a aquel de una de las deudas. Para el autor italiano, sería el siguiente caso: el deudor tiene con el acreedor dos relaciones obligatorias dinerarias, una por S/ 120,00 y la otra por S/ 100,00 y ejecuta un pago de S/ 100,00. En esta hipótesis no habría incertidumbre respecto a qué relación obligatoria se refiere el pago, por cuanto para imputar el pago a la deuda de $S / 120,00$ se requeriría el consentimiento del acreedor (Bordon, 2009, p. 321).

Díez-Picazo (1986), en principio, rechaza la imputación tácita, aunque no de manera definitiva. Para el autor español, la hipótesis es difícilmente comprensible, toda vez que, dada la homogeneidad de la prestación y la pluralidad de deudas, será difícil extraer un sentido unívoco de los actos del deudor. Hay que pensar, además, en la incoherencia que supone resolver un problema de la eventual incertidumbre sobre la dirección del pago a través de un criterio que a su vez refleja incertidumbre. Todo ello dicho, sin embargo, puede admitirse que en algunos casos existan hechos concluyentes a partir de los cuales la facultad de imputar se puede considerar ejercitada (p. 574).

El acto de imputar determina su efecto, es decir, la referencia de la atribución patrimonial (pago) a la relación obligatoria que va a ser extinguida, según la decisión del deudor. Por ello se afirma que la imputación es un negocio de destinación, pues destina la atribución patrimonial (pago) a una u otra relación obligatoria según la decisión del deudor (Bianca, 1993, p. 337).

La jurisprudencia italiana señala que la imputación por declaración del deudor está reservada únicamente cuando este efectúa el pago personalmente; no cabe en el caso del pago de tercero. No obstante, se admite la imputación efectuada por un delegado del deudor (Barchi, 2013, p. 141). Bellelli, en cambio, respecto a la legitimación para imputar por terceros, afirma que, en general, la legitimación para pagar y para recibir el pago implica, como elemento natural, la legitimación para imputar (como se citó en Bianca, 1993, p. 336). 


\section{b. Aspecto temporal de la imputación por el deudor}

Un requisito particular de la imputación por el deudor es el temporal. En efecto, de acuerdo con el artículo 1256 del Código Civil (1984) la imputación debe efectuarse "al tiempo de hacer el pago, o, en todo caso, antes de aceptar el recibo emitido por el acreedor".

En una interpretación literal, el deudor debe efectuar la imputación al momento de realizar el pago ("al tiempo de hacer el pago") o, en todo caso, antes de aceptar el recibo que emita el acreedor. En tal sentido, en virtud de lo dispuesto por el Código Civil peruano (1984), cabría una imputación ex parte debitoris que no sea simultánea a la ejecución de la prestación, siempre que ello ocurra antes de aceptar el recibo. En Italia, Bozzi explica que la doctrina prevaleciente, atribuyendo a la norma carácter dispositivo, admite también una imputación anterior al pago, con la única limitación de que no sea sucesiva a él (como se citó en Bordon, 2009, p. 297).

Con respecto a la oportunidad de la imputación por el deudor, Cazeaux y Trigo (1986), en Argentina, indican que también puede efectuarse antes de realizar el pago (p. 205). De la misma opinión es Díez-Picazo (1996), en España. En efecto, para el autor español: “La facultad de imputación es de ejercicio perentorio y tiene que realizarse en el momento mismo de efectuar el pago". No obstante, el no ejercer la facultad de imputar al momento del pago supondría una suerte de caducidad de dicha facultad $y$, en tal sentido, resulta admisible la posibilidad de hacer la imputación con anterioridad al momento del pago (Díez-Picazo, 1996, p. 524).

Sin perjuicio de lo señalado, debe tenerse en cuenta que puede admitirse una imputación tardía, pero en tal caso se requeriría que el acreedor acepte la misma confiriéndole plena eficacia.

\section{c. La prueba de la imputación del pago}

En cuanto a la carga de la prueba, Bianca (1996) señala que el deudor requerido judicial (o arbitralmente, puedo añadir) para el pago de una deuda puede limitarse a probar que ha ejecutado una prestación correspondiente a aquella respecto de la cual el acreedor exige el pago (artículo 1129 del Código Civil $^{7}$ ). En caso de que exista una pluralidad de deudas, surge la cuestión de determinar quién debe demostrar a qué deuda debe-

7 "La prueba del pago incumbe a quien pretende haberlo efectuado". 
ría ser imputado el pago. De esta manera, si el acreedor demuestra que existía una pluralidad de deudas, el deudor debe probar no solo el pago (artículo 1129 del Código Civil), sino también que se ha tratado de un pago imputado a la deuda que es objeto del litigio (pp. 345-346).

La jurisprudencia italiana tiene una posición distinta. Si un acreedor pretende el pago de una obligación en un proceso (judicial o arbitral), la carga de la prueba de la existencia de una pluralidad de deudas corresponde al acreedor. Cuando el deudor hubiera probado haber pagado, aun sin haber imputado; entonces, corresponde al acreedor que niegue la imputación del pago efectuado por el deudor a la obligación cuyo cumplimiento pretende, y probar que corresponde imputarlo a una deuda distinta. Esta orientación jurisprudencial se justifica en el hecho de que la existencia de una pluralidad de deudas y la necesaria imputación del pago constituyen circunstancias impeditivas del efecto extintivo del pago que corresponden ser probadas por el acreedor (Bordon, 2009, pp. 299-300).

\section{d. Los límites de la imputación por el deudor}

\section{(i) Límite del artículo 1257 del Código Civil: obligación que devenga intereses}

El artículo 1257 del Código Civil (1984) establece un límite al derecho potestativo del deudor de imputar el pago y, también, contiene un criterio legal de imputación: "Quien deba capital, gastos e intereses, no puede, sin el asentimiento del acreedor, aplicar el pago al capital antes que a los gastos, ni a éstos antes que a los intereses".

En efecto, el artículo citado establece un límite al derecho de elección del deudor, sancionando que, en el caso de un pago parcial aceptado por el acreedor, no pueda ser imputado primero al capital, luego a los gastos y finalmente a los intereses, si no es con el consentimiento del acreedor. Del consentimiento del acreedor de recibir un pago parcial (artículo 1221 del Código Civil de $1984^{8}$ ) no puede deducirse su renuncia a la imputación, según los criterios

8 “No puede compelerse al acreedor a recibir parcialmente la prestación objeto de la obligación, a menos que la ley o el contrato lo autoricen. Sin embargo, cuando la deuda tiene una parte líquida y otra ilíquida, puede exigir el acreedor el pago de la primera, sin esperar que se liquide la segunda". 
legales del artículo 1257. La renuncia a la imputación, en cambio, debe resultar de manera expresa y directa (Bozzi, 2009, p. 177).

La doctrina italiana advierte que la norma presupone que el acreedor acepte un pago que, siendo parcial, no respeta la regla establecida por el numeral 3 del artículo 1208 del Codice Civile y que, con base en el artículo 1181 (artículo 1221) del Código Civil, podría ser rehusado por el acreedor. En efecto, por tratarse de un pago parcial, el acreedor puede negarse a recibir el pago de intereses sin pagar capital y viceversa; un pago íntegro supone el pago conjunto del capital más los intereses. Como señala el artículo 1208, numeral 3, del Código Civil italiano (1942) referido al ofrecimiento de pago:

Para que el ofrecimiento sea válido es necesario:

$[\ldots]$

1) Que comprenda la totalidad de las sumas o de las cosas debidas, de los frutos o de los intereses y de los gastos líquidos, y una suma por los gastos no líquidos, con reserva de un suplemento, si es necesario;

$[\cdots]$

Como consecuencia de ello, debe reconocerse que el cumplimiento íntegro de la obligación se extiende a los intereses y a los gastos; pero son posibles, si el acreedor los acepta, pagos relativos solo al capital, o bien a los intereses y/o a los gastos. Se trataría, en tal caso, de pagos parciales (Breccia, 1991, p. 564). En tal sentido, si el acreedor acepta el pago parcial, el deudor no podrá pretender extinguir primero la deuda de capital antes que la de intereses.

Parte de la doctrina italiana considera que el artículo 1194 del Codice Civile (artículo 1257 del Código Civil) disciplina exclusivamente la hipótesis de pago parcial y no presupone una pluralidad de deudas, teniendo en cuenta que la deuda que tiene por objeto capital e intereses es, por su naturaleza, única (Chessa, 1996, p. 130).

En España, Estevill (1986) señala que el artículo 1173 del Código Civil español plantea la cuestión de si las dos deudas, la de capital 
y la de intereses (que se producen en razón del capital), son una pluralidad de deudas. De acuerdo con el autor español, la jurisprudencia de su país sienta que el artículo 1173 no habla de "varias deudas", como en el artículo 1172 ("El que tuviere varias deudas $[\ldots]$ "), sino de una sola en la cual existen capital e intereses ("Si la deuda produce intereses $[\ldots]$ ". ). No obstante, considera que si la deuda produce intereses, entonces:

[Se opera] por la fuerza de los propios hechos, una pluralidad de éstos y de la misma especie. [Y, más adelante, añade que] si no se hubiese pensado en la concurrencia de dos débitos, no se hubiera previsto por el legislador los riesgos o posibles situaciones conflictivas. $\mathrm{Si}$, como dice la jurisprudencia, se tratara de una sola deuda, compuesta por capital y rentas, no sería de prever inconveniente alguno. El deudor pagando íntegramente la deuda cumpliría la obligación establecida y, por otra parte, no le sería posible, sin convenirse con el acreedor, dividir en partes su pago [...]. [Finalmente, concluye:] así, pues, se trata de deudas distintas [y el hecho de que la una es fuente de la otra, no rompe la consideración de que se trata de deudas diferentes]. (Estevill, 1986, p. 348)

Hernández (1988) explica que ha de tratarse de dos créditos derivados de una misma relación obligacional: uno representado por el capital; y el otro, por los intereses que produce el capital (p. 315).

Osterling y Castillo (1996) explican que el supuesto del artículo 1257 del Código Civil:

No se basa en que existan -necesariamente- prestaciones surgidas de distintas fuentes, o, incluso, de diferentes obligaciones; simplemente está aludiendo a que una misma obligación pueda tener diversas prestaciones de la misma naturaleza, con caracteres de homogeneidad, pero por distintos conceptos.

[Más adelante reiteran lo dicho:]

Estamos frente a una sola obligación, que consiste en el pago de diversas prestaciones (aquellas que generan el deber de devolver el capital y de pagar los gastos e intereses). Queda claro, entonces, que la concepción del artículo 1257 es totalmente distinta a la del artículo 1256. (Osterling y Castillo, 1996, pp. 333-335) 
El acreedor puede consentir la eliminación del límite y permitir que primero se impute a capital (también puede consentir pagos parciales). No obstante, en este caso, conforme al artículo 1232 del Código Civil ${ }^{9}$, de imputar el pago a capital antes que a intereses, deberá cuidar de hacer "reserva de intereses" para que no opere la presunción prevista en dicho artículo.

El límite del artículo 1257 del Código Civil implica la ineficacia del acto de imputación por el deudor en la parte que da la precedencia al capital respecto a los intereses y a los gastos. El acreedor puede remover tal ineficacia con su asentimiento.

De acuerdo con Osterling (2007), el orden de imputación establecido en el artículo 1257 del Código Civil tiene justificación plena. El ponente del Libro de Obligaciones explica:

En materia civil, los intereses no generan intereses, salvo que sean capitalizados. La capitalización, a su vez, solo puede pactarse por escrito después de contraída la obligación, siempre que medie no menos de un año de atraso. Esta norma sobre el anatocismo, prevista por el artículo 1250 del Código, es de orden público.

[...] Los gastos suelen generar intereses legales, salvo acuerdo sobre pago de intereses convencionales. El capital, por su parte, usualmente genera intereses convencionales $\mathrm{y}$, a falta de pacto, intereses legales. [Luego, concluye:] dentro de este planteamiento razonable, como elemental medida de protección para el acreedor ante el deudor moroso, que éste, salvo acuerdo en contrario con el propio acreedor, debe pagar en primer término los intereses, que solo si se capitalizan generarían intereses; luego, los gastos, que usualmente solo originan intereses legales, inferiores a los convencionales; $y$, finalmente, el capital, que usualmente genera intereses convencionales superiores a los legales. (Osterling, 2007, p. 178)

De la misma opinión es Di Majo, para quien la regla del artículo 1194 del Codice Civile ${ }^{10}$ (artículo 1257 del Código Civil) está esta-

9 "El recibo de pago del capital otorgado sin reserva de intereses hace presumir el pago de éstos, salvo prueba en contrario".

10 "El deudor no puede imputar el pago al capital antes a los intereses y a los gastos, sin el consentimiento del acreedor. El pago hecho a cuenta de capital y de los intereses debe ser imputado primero a los intereses". 
blecida a favor del acreedor (favor creditoris), puesto que si este fuera constreñido a aceptar la imputación al capital antes que a los intereses, perdería el beneficio de la ulterior fructificación del capital (Chessa, 1996, p.130).

En efecto, teniendo en cuenta la prohibición del anatocismo (los intereses no pueden devengar intereses) establecida en el Código Civil (artículo 1249), resulta claro que la disposición del artículo 1257 del Código Civil protege la posición del acreedor del riesgo de perder el beneficio que sobre el capital se devenguen ulteriores intereses.

Como señala Moisset de Espanés (2000), si el deudor pretendiese pagar primeramente el capital, "perjudicaría al acreedor, porque estaría disminuyendo la fuente productora de los intereses" (p. 124). De la misma opinión es Díez-Picazo, quien, al comentar el artículo 1173 del Código Civil español, considera que se trata de una norma de protección del "acreedor que no puede ver disminuida la fuente de producción de los futuros intereses, sin que estos últimos se encuentren satisfechos" (Bordon, 2009, pp. 306-307).

En efecto, en la mayoría de las legislaciones se prohíbe que los intereses devenguen intereses (capitalización de intereses o anatocismo). Se ha expresado como fundamento de la prohibición la protección del deudor. Se trataría de evitar que el acreedor se aproveche del estado de necesidad del deudor, dado que el anatocismo incrementa la productividad del capital. En tal sentido, Vidal Ramírez (2009) explica que "las prohibiciones y restricciones al anatocismo se han justificado siempre en el temor a su abuso y a su utilización como arma funesta en manos de usureros" (pp. 99-140).

La doctrina, de manera unánime, ha considerado que la obligación de pagar intereses es una obligación accesoria. Así Díez-Picazo (1996) afirma: “La obligación de pagar intereses es una obligación accesoria de la obligación principal de restitución o de entrega del capital disfrutado o utilizado" (p. 282). No obstante, pocas veces encontramos una explicación convincente sobre el carácter accesorio de la obligación de pagar intereses.

Bianca (1993) explica: “La accesoriedad de la obligación de los intereses respecto a aquellas que inciden en su momento genético 
[...] no excluye que, una vez existente, la obligación adquiere identidad autónoma, pudiendo extinguirse o sobrevivir prescindiendo de la suerte del capital" (p. 177).

En el mismo sentido, Mariconde (1977) señala:

La obligación principal puede nacer y existir para sí misma y por sí misma; en cambio, la obligación accesoria depende de la principal, durante toda su existencia, o sólo en el período de su formación. La dependencia de los intereses existe únicamente en el lapso de su devengamiento $\mathrm{y}$, en su virtud, la obligación accesoria no puede "nacer" (empleando un término naturalista) sin que preexista la obligación principal. (p. 43)

En tal sentido, debemos tener presente que los intereses son debidos en medida porcentual del capital. Por tanto, existe una relación de subordinación y dependencia con el capital; así, por ejemplo, el monto de los intereses se va devengando y aumenta o disminuye en relación con el aumento o disminución del capital. La relación de accesoriedad se establece entre el capital y el interés en su origen, que no es lo mismo que afirmar que los intereses son una prestación accesoria, en la que su existencia depende de la principal.

Después de que los intereses se han devengado, adquieren existencia jurídica propia y pueden exigirse independientemente del capital; por tanto, el pago del capital no extingue la deuda de intereses. Desde esta perspectiva, el capital y los intereses, en su calidad de frutos, son bienes accesorios a dicho capital, y es desde esta relación que se aplica el principio accesorium sequitor principale.

Por lo expuesto, la disposición del artículo 1257 del Código Civil impide que el deudor pueda imputar su pago primero al capital, puesto que, de tratarse de un pago parcial, se reducirían los intereses que se devenguen ulteriormente $\mathrm{y}$, en caso de pago total del capital, los intereses devengados no generarían intereses. La solución que brinda el artículo 1257 del Código Civil contradice el principio favor debitoris que inspira gran parte del Libro de las Obligaciones del Código Civil.

Cazeaux y Trigo (1986) consideran que el artículo 776 del Código Civil argentino (similar al artículo 1257 del Código Civil) se aplica 
indistintamente a intereses compensatorios o moratorios. Concuerdo con tal posición, pero, entonces, cabe preguntarse cuál es el orden de imputación entre ellos (p. 206).

$\mathrm{Al}$ respecto, resulta interesante la solución que brinda el artículo 785 del Código Civil portugués (1966), el cual dispone:

1. Cuando, además del capital, el deudor está obligado a pagar gastos o intereses, o a indemnizar al acreedor como consecuencia de la mora, la prestación que no llegue a cubrir todo lo que es debido se presume hecha por cuenta, sucesivamente, de los gastos, de la indemnización, de los intereses y del capital.

2. La imputación al capital sólo puede hacerse en el último lugar, salvo si el acreedor acepta que se haga antes.

Como bien lo explica Moisset de Espanés (2000), la "indemnización" a la que se refiere el artículo citado del Código Civil portugués corresponde a nuestros "intereses moratorios", estableciendo una preferencia de cobro a estos por sobre los intereses compensatorios que devengue el capital (p. 113).

Respecto a los gastos, debe tenerse en cuenta que algunos Códigos Civiles, como el francés (artículo 1254), el español (artículo 1173) y el argentino (artículos 776 y 777), no hacen referencia a ellos.

Osterling y Castillo (1996) recurren al diccionario de la Real Academia de la Lengua Española para definir la palabra gasto; luego, afirman: "En realidad los gastos constituyen todos aquellos desembolsos que se hayan hecho conducentes a la celebración del contrato o, hablando en singular, al nacimiento de la obligación de que se trate". Más adelante, agregan: "Aclaramos, sin embargo, que la palabra gasto también puede referirse a las expensas en las que puede haber incurrido el acreedor para la cobranza del capital e intereses adeudados" (p. 333).

El Código Civil no tiene una definición de gastos o expensas. En el contexto del artículo 1257 del Código Civil, los gastos son desembolsos efectuados por el acreedor, pero que corresponden ser asumidos por el deudor. No se limitan, como señalan Osterling y Castillo (1996), a los desembolsos conducentes a la celebración del contrato, sino que comprenden los desembolsos efectuados para 
la ejecución de la prestación, así, por ejemplo, los gastos de entrega del bien o los gastos de transporte del bien a un lugar diferente del de cumplimiento.

El BGB (§ 36711), el Código Civil portugués (1966) (artículo 785) y los Principios sobre los Contratos Comerciales Internacionales (UNIDROIT, 2010) (artículo 6.1.1212) establecen un orden distinto: en primer lugar a los gastos, luego a los intereses $\mathrm{y}$, finalmente, al capital.

El artículo 1266 del Código Civil de 1936 disponía el mismo orden de las normas anteriormente citadas, diferenciándose del actual Código Civil. El Código Civil derogado (1936) señalaba: "El que debe capital, intereses y gastos, no puede, sin consentimiento del acreedor, aplicar el pago al capital antes que a los intereses, ni a éstos antes que a los gastos". Como puede apreciarse, el Código Civil de 1936 indicaba que la imputación debía hacerse primero a los gastos y luego a los intereses. No existen referencias en la Exposición de Motivos respecto a las razones del cambio, aunque Moisset de Espanés (2000) explica:

Solamente nos queda imaginar que se ha pensado que los "gastos" o "expensas", aunque configuran una obligación autónoma, tienen más las características de una deuda que a su vez puede generar frutos; es decir, otros intereses distintos de la deuda principal, razón por la cual se prefiere dar primacía en la imputación a todas las deudas de intereses, para proseguir con los gastos, y concluir con el capital originario. (p. 115)

Guzmán Ferrer (1982), al comentar el artículo 1266 del Código Civil peruano de 1936, manifiesta que la preferencia de los gastos sobre los intereses armonizaba las reglas de la imputación con las

11 “(1) Si además de la prestación principal el deudor debe pagar intereses y costes, la prestación que no basta para satisfacer la deuda por entero será en primer lugar imputada a los costes, después a los intereses y, por último, a la prestación principal".

12 “(1) Un deudor de varias obligaciones dinerarias al mismo acreedor puede especificar al momento del pago a cuál de ellas pretende que sea aplicado el pago. En cualquier caso, el pago ha de imputarse en primer lugar a cualquier gasto, luego a los intereses debidos y finalmente al capital". 
que reglan la prelación de los créditos, haciendo referencia al artículo 112 de la Ley 7566, Ley de Quiebras (p. 1449).

Los gastos, a diferencia de los intereses que constituyen una obligación accesoria, son una obligación autónoma. Así, por ejemplo, supongamos que Primus celebra con Secundus un contrato de compraventa en virtud del cual el primero se obliga a transferir la propiedad del bien $\mathrm{X}$ al segundo, $\mathrm{y}$ este a pagarle al primero un precio en dinero. $\mathrm{Si}$ las partes pactan que los gastos del transporte del bien $X$ serán de cargo del comprador, pero son desembolsados por el vendedor, entonces, Secundus (comprador) debe a Primus (vendedor) el precio y los gastos del transporte. ¿Por qué en este caso debería efectuarse el pago a los gastos antes que al capital?

Osterling (2007) parece justificar el orden sobre la base de que los gastos solo originan intereses legales, mientras que el capital usualmente genera intereses convencionales que son superiores a los legales (p. 178). En España, Estevill (1986) señala que solamente no procederá la imputación legal ex artículo 1173 del Código Civil español (similar al 1257 de nuestro Código Civil) cuando el acreedor otorgue recibo por el capital sin reserva de intereses (primer párrafo del artículo 1110 del Código Civil español).

El primer párrafo del artículo 1110 del Código Civil español (1889) establece lo siguiente: "El recibo del capital por el acreedor, sin reserva alguna respecto a los intereses, extingue la obligación del deudor en cuanto a éstos [...]". De acuerdo con Díez-Picazo (1996), parafraseando el artículo citado, "el recibo del capital por el acreedor, sin reserva alguna respecto de los intereses, extingue la obligación del deudor en cuanto a éstos", lo cual permitiría afirmar que para el Código Civil español no se da una presunción (p. 286).

En el Código Civil peruano (1984), el artículo 1232 dice: “El recibo de pago del capital otorgado sin reserva de intereses hace presumir el pago de éstos, salvo prueba en contrario". El artículo citado se tomó del artículo 1246 del Código Civil de 1936 y es similar al artículo 1908 del Código Civil francés (1984), el cual dispone: "La quittance du capital donnée sans réserve des intérêts, en fait présumer le payement, et en opère la libération". 
El artículo 1232 tiene como fundamento el artículo 1257 del Código Civil (1984). En efecto, dado que, conforme al artículo 1257 del Código Civil (1984), el deudor no puede, sin el consentimiento del acreedor, imputar el pago al capital antes que a los intereses, se presume, si existe un recibo de pago del capital (sin reserva), que los intereses ya fueron pagados.

- La imputación en el caso de pago de intereses con tasa superior a la tasa máxima fijada por el Banco Central de Reserva

Una hipótesis particular es aquella en la cual el deudor paga intereses con una tasa superior a la tasa máxima fijada por el Banco Central de Reserva. En tal caso, conforme al segundo párrafo del artículo 1243 del Código Civil (1984), el deudor podrá elegir entre requerir la devolución del exceso o imputarlo al capital (Díez-Picazo, 1996, p. 286).

\section{¿Es inaplicable el artículo 1257 del Código Civil a la responsa- bilidad extracontractual?}

La jurisprudencia italiana es firme en negar la aplicabilidad del artículo 1194 del Codice Civile (artículo 1257 del Código Civil peruano) a la responsabilidad extracontractual, en la cual los anticipos a cuenta del resarcimiento del daño deben imputarse al capital, más bien que a los intereses, reduciendo así el monto del daño por liquidar con la consiguiente ventaja para el deudor (Bordon, 2009, p. 308). Así, el resultado es exactamente contrario a la ratio del artículo 1994 (artículo 1257 del Código Civil peruano).

La casación considera:

En tema de resarcimiento de daños, los adelantos efectuados en favor del dañado en el curso del proceso de liquidación no son imputables a los intereses, no siendo aplicable el criterio previsto por el artículo 1194 c.c., que presupone una deuda pecuniaria en especie inexistente hasta la liquidación del daño, ni pudiéndose configurar una obligación autónoma, si bien accesoria, relativa a los intereses que en tema de obligación resarcitoria constituyen una componente del daño, y por consiguiente de la única deuda. (Bordon, 2009, p. 308).

Por tanto, los anticipos deben imputarse al capital, mientras que los intereses deben ser calculados sobre el importe entero del 
daño con efecto desde la fecha del evento dañoso hasta la fecha de pago de los adelantos (Bordon, 2009, p. 308).

Posteriormente, la jurisprudencia italiana ha confirmado que la imputación de pago ex artículo 1194 (artículo 1257 del Código Civil peruano) presupone, en realidad, la existencia simultánea de la liquidez y de la exigibilidad de ambos créditos. Es decir, de aquel relativo al capital y al accesorio por intereses y gastos. Por tanto, en materia de resarcimiento de daños, los adelantos de sumas de dinero efectuados a favor del acreedor antes de la liquidación (judicial o negocial) no son imputables a los intereses, no siendo aplicable el criterio previsto por el artículo 1194 del Codice Civile (artículo 1257 del Código Civil peruano), que presupone la existencia de un débito pecuniario, inexistente hasta la liquidación del daño. Los adelantos a cuenta deberían, entonces, imputarse al capital, sin que se pueda aplicar el artículo 1194 (artículo 1257 del Código Civil peruano) (Bordon, 2009, p. 309).

Para Bordon (2009), sin embargo, la tesis adoptada por la jurisprudencia italiana, que exige la simultánea liquidez y exigibilidad de los créditos por capital y por intereses, no convence plenamente. En efecto, queda confirmado que precisamente la jerarquía que el artículo 1193 del Codice Civile establece entre deuda vencida y deuda no vencida desmiente que se requiera para la imputación del pago la contemporánea exigibilidad de los créditos. Finalmente, el autor señala que la inaplicabilidad del artículo 1194 a la responsabilidad extracontractual genera una ventaja injustificada para el deudor de responsabilidad extracontractual. Respecto a este último tema, la jurisprudencia italiana ha negado que la disparidad en el trato entre el deudor de responsabilidad extracontractual y el deudor de una obligación pecuniaria sea inconstitucional, pues se trataría de situaciones no homogéneas (p. 310).

¿Es inaplicable el artículo 1257 del Código Civil a la responsabilidad extracontractual?

Veamos. El artículo 1985 del Código Civil (1984) señala:

La indemnización comprende las consecuencias que deriven de la acción u omisión generadora del daño, incluyendo el lucro cesante, 
el daño a la persona y el daño moral, debiendo existir una relación de causalidad adecuada entre el hecho y el daño producido. El monto de la indemnización devenga intereses legales desde la fecha en que se produjo el daño [cursivas añadidas].

De acuerdo con el artículo citado, el monto de la indemnización devenga intereses con la tasa del interés legal desde la fecha en que se produjo el daño.

La cuestión que se plantea es si los intereses que se devengan son moratorios. Al respecto, Cárdenas Quirós (1993) se pregunta:

¿Con qué carácter operan los intereses legales en el caso del segundo párrafo del artículo 1985? En efecto, en la doctrina nacional se discute si los intereses a los que se refiere el artículo 1985 del Código Civil son intereses moratorios. Quienes niegan que se trate de intereses moratorios sustentan su posición en la idea de que el deudor no incurre en mora si es que la deuda es ilíquida, de ahí el brocardo in illiquidis non fit mora. (p. 21) $)^{13}$

Debe tenerse en cuenta que la obligación resarcitoria es ilíquida mientras no sea determinada en su existencia (quid) y cuantía (quantum) en el curso del proceso de liquidación (judicial o arbitral), o mientras no sea liquidada convencionalmente. También es necesario considerar el último párrafo del artículo 1256 del Código Civil (1984), el cual establece que "sin el asentimiento del acreedor, no se imputará el pago parcialmente a una deuda ilíquida [cursivas añadidas] o no vencida".

En tal sentido, si la víctima del daño consiente recibir anticipos a cuenta del resarcimiento de daños, se debe entender que está aceptando que se impute el pago a una deuda ilíquida (artículo 1256 del Código Civil de 1984). Superado el primer límite, nos enfrentamos al segundo establecido en el artículo 1257 del Código

13 La doctrina italiana posterior al Código Civil de 1942 se aleja del brocardo in illiquidis non fit mora, lo que se desprende del artículo 1219, inciso 1, del Codice Civile, que establece la mora de pleno derecho cuando la deuda derive de un hecho ilícito. De acuerdo con Bianca (1993), el autor del ilícito cae automáticamente en mora y a la víctima le corresponden los intereses moratorios desde el momento mismo que el daño se verifica (p. 187). 
Civil (1984) y, en tal sentido, este anticipo a cuenta debe imputarse a los intereses antes que al capital, salvo que la víctima del daño (acreedor) consienta un orden de imputación distinto.

(ii) Límites establecidos en el último párrafo del artículo 1256 del Código Civil

El segundo párrafo del artículo 1256 del Código Civil (1984) reconoce límites a la imputación por el deudor. Estos límites no son recogidos por las legislaciones extranjeras más representativas en la parte relativa a la imputación del pago, pero se reconocen como límites indirectos. Este es el caso, por ejemplo, del Código Civil francés (1804); así el derogado artículo 1244 del Code Civil señalaba: "Le débiteur ne peut point forcer le créacier à recevoir en partie le paiement d'une dette, même divisible".

Al respecto, Bianca (1993) explica que el derecho de imputar por parte del deudor encuentra un límite indirecto en la facultad del deudor de rehusar un pago parcial. Por tanto, si la imputación por el deudor importa un pago parcial, el acreedor puede, legítimamente, rehusar la imputación en virtud del artículo 1181 del Codice Civile (artículo 1221 del Código Civil peruano). Por ejemplo, si el deudor tiene dos deudas, una de 120,00 soles y otra de 180,00 soles, y realiza un ofrecimiento de pago de 140,00 soles imputándolo a la segunda deuda, estaríamos ante un pago parcial que podría ser rehusado por el acreedor. Lo mismo ocurre con el Código Civil español y con el Código Civil alemán (BGB) (p. 339).

El Código Civil argentino (1871) tiene una posición más parecida a la peruana y en el artículo 774 indica: "La elección del deudor no podrá ser sobre deuda ilíquida, ni sobre la que no sea de plazo vencido".

- Pago parcial

El derecho de imputación por el deudor encuentra un límite en la facultad del acreedor de rehusar un pago parcial, conforme con lo previsto en el artículo 1221 del Código Civil (1984) ${ }^{14}$. En tal sentido,

14 "No puede compelerse al acreedor a recibir parcialmente la prestación objeto de la obligación, a menos que la ley o el contrato lo autoricen $[\ldots]$ ". 
de acuerdo con el artículo 1256: "[...] sin el asentimiento del acreedor, no se imputará el pago parcialmente [cursivas añadidas] a una deuda ilíquida o no vencida". Según el comentario de Osterling (2007) acerca del artículo anterior, la referencia a pagos parciales es "congruente con lo previsto por el artículo 1221 del Código [...]" (p. 177).

La imputación voluntaria por el deudor, entendida como norma que tutela el interés del solvens, no priva al acreedor de la facultad de rehusar un pago parcial (artículo 1221 del Código Civil). De acuerdo con Iannicelli (2008): "En caso de conflicto entre las dos normas, prevalece por tanto aquella que tutela al acreedor y la unidad de la prestación" (p. 572)

Hernández (1988) señala:

La prestación realizada deberá representar el pago íntegro de los créditos a que se haga la imputación. Una imputación que cubra parcialmente uno de los créditos sólo es admisible en la medida en que, conforme al artículo $1169^{15}$, quepa el pago parcial, o por aplicación del párrafo segundo del artículo 1174. En particular, si uno de los diversos créditos consta de una parte líquida y otra ilíquida, la imputación podrá hacerse en la parte líquida. (p. 572)

Cazeaux y Trigo (1986) consideran que, aunque no lo diga el Código Civil argentino:

Se admite asimismo que si la suma ofrecida alcanzare a pagar íntegramente una de las deudas y sólo en parte la otra; el deudor no podría imputar el pago a esta última, por cuanto ello importaría imponer al acreedor un pago parcial, en contra de lo dispuesto en el artículo 742 del Código Civil. (p. 206)

\section{- Deuda ilíquida}

El derecho de imputación por el deudor encuentra un límite en la facultad del acreedor de rehusar el pago de una deuda ilíquida de acuerdo con el artículo 1221 del Código Civil (1984). En tal senti-

15 "A menos que el contrato expresamente lo autorice, no podrá compelerse al acreedor a recibir parcialmente las prestaciones en que consista la obligación [...]". 
do, conforme con el artículo 1256: "[...] sin el asentimiento del acreedor, no se imputará el pago [cursivas añadidas] parcialmente a una deuda ilíquida [cursivas añadidas] o no vencida".

La deuda es ilíquida cuando existe una indeterminación cuantitativa que trae como consecuencia una imposibilidad de establecer si resulta o no íntegro el pago de la deuda (Cazeaux y Trigo, 1986, p. 205). Así, por ejemplo, supongamos que Primus le debe a Secundus S/ 100,00. Asimismo, Primus ha reconocido ser responsable de un daño causado a Secundus y la determinación (quantum) del daño será establecida mediante arbitraje (deuda ilíquida). Entonces, si Primus paga S/ 100,00 a Secundus no puede imputarlos a la deuda ilíquida, salvo que el acreedor lo consienta.

La referencia a deuda ilíquida está en relación con el pago parcial, conforme con lo previsto por el artículo 1221 del Código Civil (1984), que señala ${ }^{16}$ :

No puede compelerse al acreedor a recibir parcialmente la prestación objeto de la obligación, a menos que la ley o el contrato lo autoricen.

Sin embargo, cuando la deuda tiene una parte líquida y otra ilíquida, puede exigir el acreedor el pago de la primera, sin esperar que se liquide la segunda.

En efecto, el pago de una deuda ilíquida podría conllevar un pago parcial ${ }^{17}$, por lo que, según el primer párrafo del artículo citado, no puede compelerse al acreedor a recibir un pago respecto a una deuda ilíquida. No obstante, el segundo párrafo del artículo transcrito permite, excepcionalmente, el pago parcial de la obligación cuando esta tenga una parte líquida, sin esperar la liquidación de la parte restante.

16 Este artículo tiene como antecedente el artículo 1160 del Código Civil español: "A menos que el contrato expresamente lo autorice, no podrá compelerse al acreedor a recibir parcialmente las prestaciones en que consista la obligación. Sin embargo, cuando la deuda tuviera una parte líquida y otra no líquida, podrá exigir el acreedor y hacer el deudor el pago de la primera sin esperar a que se liquide la segunda".

17 Ello sin perjuicio de tener en cuenta que la única manera de saber si realmente se da un pago parcial es conociendo cuál es el monto definitivo de la deuda. 
Debe tenerse en consideración que el segundo párrafo del artículo 1221 del Código Civil (1984) faculta al acreedor a exigir el pago de la parte líquida ("puede exigir el acreedor"), pero este puede rechazar justificadamente el ofrecimiento de pago de la parte líquida efectuado por el deudor.

En España, Estevill (1986), siguiendo a Bercovitz, considera que para la imputación de pagos no es necesario el requisito de la liquidez de las deudas (p. 345).

\section{- Deuda no vencida}

El derecho de imputación del deudor encuentra un límite en la facultad del acreedor de rehusar un pago a una deuda no vencida conforme con lo previsto en el artículo 1256 del Código Civil (1984): "[...] sin el asentimiento del acreedor, no se imputará el pago parcialmente a una deuda ilíquida o no vencida [cursivas añadidas]". Esta limitación tiene como antecedente el artículo 774 del Código Civil argentino, el cual establece: "La elección del deudor no podrá ser sobre deuda ilíquida, ni sobre la que no sea de plazo vencido".

Osterling y Castillo (1986), comentando el artículo 1256 del Código Civil y citando a los argentinos Alterini, Ameal y López Cabana, afirman que el pago no podrá hacerse antes del plazo, sino de común acuerdo (en el caso de la deuda no vencida). No obstante, creo que la limitación de la imputación a la deuda no vencida no puede ser interpretada literalmente, sino de manera sistemática, y la afirmación de los autores argentinos citados debe ser puesta en su contexto (p. 328).

En efecto, el artículo 1256 debe ser concordado con el artículo 179 del Código Civil (1984), que establece: "El plazo suspensivo se presume establecido en beneficio del deudor, a no ser que del tenor del instrumento o de otras circunstancias, resultase haberse puesto a favor del acreedor o de ambos".

Con relación al beneficio del plazo, se señalan dos posiciones ${ }^{18}$. La primera dispone que la solución de la imputación del pago consti-

$18 \mathrm{Al}$ respecto, es preciso comentar que el debate suscitado sobre el punto ha sido ardoroso y ambas posturas cuentan con sostenedores de primera línea, tanto en Francia, como en Alemania e Italia, y sin duda ha de costar trabajo a la jurisprudencia peruana resolverse en uno $u$ otro sentido. 
tuye una excepción al principio general del beneficio del plazo; esto quiere decir que cuando entre un mismo deudor y un mismo acreedor existen varias relaciones obligatorias de igual naturaleza, el deudor no podrá hacer valer el beneficium debitoris y, por lo tanto, no podrá imputar el pago a una deuda no vencida. Se argumenta, en defensa de esta posición, que el crédito del acreedor ante una pluralidad de deudores se torna más inseguro, por lo que debe buscarse la paridad. La otra posición considera que se requerirá el asentimiento del acreedor solamente cuando el término se encuentre establecido en beneficio exclusivo de él o cuando lo esté a favor de ambas partes (Moisset de Espanés, 2000, p. 117).

Por mi parte, me adhiero a la segunda posición. En efecto, el plazo en beneficio del deudor suspende la exigibilidad de la prestación por parte del acreedor antes del vencimiento del término, pero el deudor puede cumplirla anticipadamente, no existiendo razón alguna para que, en el caso de que el deudor contraiga una nueva relación obligatoria con el mismo acreedor, el plazo se transforme en beneficio del acreedor, variando sus efectos. Por lo demás, es lógico pensar que el deudor pueda, en virtud del beneficio del plazo, liberarse de una deuda que le resulta más onerosa y que aún no está vencida.

El artículo 570 del Código Civil argentino (1871) señala:

El plazo puesto en las obligaciones se presume establecido para ambas partes, a no ser que, por el objeto de la obligación o por otras circunstancias, resultare haberse puesto a favor del deudor o del acreedor. El pago no podrá hacerse antes del plazo, sino de común acuerdo.

Como puede apreciarse, el Código Civil argentino, a diferencia del peruano, establece que el plazo se presume establecido en beneficio de ambas partes, lo cual justifica plenamente el sentido del artículo 774, que prohíbe la imputación a una deuda no vencida. En tal sentido, Cazeaux y Trigo (1986), en cuanto a la prohibición que establece el Código Civil argentino (artículo 774) de imputar el pago a deudas no vencidas, indican que "la razón del precepto legal obedece a que dicha modalidad está impuesta en beneficio de las dos partes de la relación obligatoria [...]" (p. 205). 
León Barandiarán (1956) explica en su comentario al artículo 1264 del Código Civil peruano de 1936:

En cuanto a la exigencia de que la deuda sea de plazo vencido, es de observar que su fundamento sólo puede explicarse si el plazo está instituido a favor del acreedor, o de ambas partes, acreedor y deudor, pues entonces imputar el pago de una deuda no vencida sería desconocer un derecho del acreedor. Pero si el plazo está instituido a favor del deudor, no hay inconveniente alguno para que el deudor impute el pago a una deuda aún no vencida, ya que en tal circunstancia no hace sino renunciar a un derecho que exclusivamente a él correspondía. Según el número 1112, el plazo se presume establecido a favor del deudor. Y, no obstante, el art. 1264 prohíbe que la imputación pueda recaer en una deuda de plazo no vencido, salvo asentimiento del acreedor. Hay, pues, implicación entre uno y otro precepto. (p. 346)

Y, luego, añadía:

Pero se trata de una implicación aparente. El deudor puede imputar el pago a una deuda cuyo plazo resulta vencido por la propia determinación de aquél, desde que cabalmente se está en el caso de un plazo que puede ser renunciado por el obligado. Sólo si el plazo se ha estipulado a favor del acreedor, o de ambos contratantes, la imputación sería improcedente, si el deudor destina el pago a la deuda sujeta a plazo. (León Barandiarán, 1956, p. 346)

En España, de acuerdo con Estevill (1986), conforme al artículo 1127 del Código Civil ${ }^{19}$ (el plazo se presume establecido en beneficio de ambas partes), el deudor no podrá pretender imputar un desplazamiento patrimonial (pago) a una de aquellas obligaciones, cuando el momento temporal de su vencimiento se hubiere creado en favor de ambas partes, o si resultase puesto en favor del acreedor. Si el plazo estuviera en beneficio del deudor, este podría renunciar y con ello posibilitaría la imputación de pagos (p. 333).

19 "Siempre que en las obligaciones se designa un término, se presume establecido en beneficio del acreedor y deudor, a no ser que el tenor de aquéllas o de otras circunstancias resultara haberse puesto a favor del uno o del otro". 


\section{(iii) Lo convenido en el negocio constitutivo de la relación obligatoria}

De acuerdo con Díez-Picazo (1996) y Estevill (1986), una limitación de la facultad del deudor de llevar a cabo la imputación de pagos puede resultar de lo dispuesto en el negocio constitutivo de la relación obligatoria. Para los referidos autores, las normas sobre la imputación del pago del Código Civil tienen carácter supletorio, de tal manera que nada impide que las partes introduzcan en el negocio jurídico constitutivo de la relación obligatoria criterios de imputación de pagos que sean diferentes de los legales. Del mismo modo, no habría inconveniente para que la facultad del deudor de imputar pueda quedar limitada convencionalmente, a través de especiales requisitos o del cumplimiento de determinadas formalidades (Díez-Picazo, 1996, p. 525; Estevill, 1986, p. 334).

\subsection{Imputación por el acreedor}

A falta de imputación por el deudor (a parte debitoris), el artículo 1258 del Código Civil (1984) contempla la posibilidad de que el acreedor efectúe la imputación (a parte creditoris). La imputación por el acreedor tiene, pues, carácter subsidiario ${ }^{20}$ :

Cuando el deudor no ha indicado a cuál de las deudas debe imputarse el pago, pero hubiese aceptado recibo del acreedor aplicándolo a algunas de ellas, no puede reclamar contra esta imputación, a menos que exista causa que impida practicarla.

Si el deudor no ejercita la facultad de imputación, tal facultad puede ser ejercitada por el acreedor.

En mi opinión, el artículo citado está estructurado al revés ${ }^{21}$. En efecto, creo que debe ser leído de la siguiente manera: a falta de la declaración unilateral del deudor imputando el pago (segundo párrafo), la imputación puede ser efectuada por el acreedor observando las indi-

20 El Código Civil mexicano no prevé la imputación a parte creditoris. Si el deudor no realiza la imputación, se aplican los criterios de imputación legal.

21 Artículo 1265 del Código Civil de 1936.- Cuando el deudor no ha indicado a cuál de las deudas debe hacerse la imputación, pero hubiese aceptado recibo del acreedor imputando el pago a alguna de ellas determinadamente, no podrá reclamar contra esta aplicación, a menos que hubiese causa que invalide el acto. 
caciones contenidas en el primer párrafo; es decir, la manifestación de voluntad del acreedor respecto a cuál de las deudas imputará el pago se hará en el recibo.

\subsubsection{Aspectos formales y temporales}

De acuerdo con Bianca (1993) y Bozzi (2009), incluir la declaración de imputación en el recibo constituye un requisito de forma que pertenece a la tradición del instituto. Tal requisito presupone la expedición del recibo por parte del acreedor $\mathrm{y}$, por tanto, la posibilidad de una declaración accesoria al recibo. A falta de recibo, el acreedor puede ejercitar su derecho de imputación con una declaración autónoma, siempre que esta sea prontamente enviada al deudor. Esto permitiría una mayor adecuación a la práctica de los negocios, la cual prevé nuevas formas de pago que algunas veces no consisten propiamente en la entrega de un recibo (Bianca, 1993, p. 341; Bozzi, 2009, p. 178). Osterling (2007) parece no compartir esta posibilidad, por cuanto, al comentar el artículo 1258 del Código Civil (1984), señala: “[...] el acreedor puede efectuar la imputación del pago solo [cursivas añadidas] en el recibo que otorga al deudor" (p. 178).

Bozzi (2009), sin embargo, afirma que no puede considerarse que la imputación creditoria pueda ser efectuada después de la entrega de un recibo, sin que esta sea desprovista de la declaración accesoria de imputación.

Debe considerarse, sin embargo, que el art. 1195 c.c. [artículo 1258 del Código Civil], más allá de requerir un requisito formal, pone también un límite de orden temporal análogo a aquél que es puesto para la declaración de imputación del deudor. (Bozzi, 2009, p. 178)

La razón de este límite temporal previsto en el artículo 1258 del Código Civil, así como para aquella impregnada en la norma del artículo 1256 del Código Civil, se reconoce en la exigencia de conferir estabilidad y certidumbre a la relación, de manera de consentir también un oportuno y provechoso ejercicio de los derechos reconocidos a las partes.

\subsubsection{La naturaleza jurídica de la imputación a parte creditoris}

La imputación por el acreedor, como la imputación por el deudor, es un negocio jurídico unilateral de destinación; es decir, destina la atribución patrimonial (pago) a una relación obligatoria según la decisión del acreedor. La eficacia de la imputación a parte creditoris no depende de la 
aceptación del deudor. En tal sentido, la referencia del artículo 1256 del Código Civil a "aceptar" el recibo también debe ser aclarada.

En efecto, la expresión "aceptar el recibo" podría hacernos pensar en la aceptación de la imputación, y ello nos llevaría a una imputación convencional descartando el carácter unilateral del acto de imputación. Esta conclusión, sin embargo, no es exacta. En estricto, la aceptación tiene por objeto el documento (recibo) y está dirigida a obtener la prueba del pago; no se trata de aceptar la imputación del acreedor que consta en dicho documento. No rechazar el recibo no tiene el significado de una manifestación de voluntad, sino que asume el valor de una aquiescencia a la imputación efectuada por el acreedor (Bianca, 1983, p. 340). No obstante, esta posición no es pacífica. El artículo 1195 del Código Civil italiano (1942) establece: "Quien, teniendo una pluralidad de deudas, acepte recibo en el cual el acreedor ha declarado imputar el pago a una de ellas, no puede pretender una imputación distinta, salvo que haya habido dolo o sorpresa por parte del acreedor". Esta norma reproduce con exactitud lo dispuesto por el artículo 1255 del Código Civil francés 22 . Ya en una primera lectura se advierte que la imputación por el acreedor tiene un carácter meramente subsidiario.

Chessa (1996) señala que la jurisprudencia y una parte considerable de la doctrina italiana divergen respecto a la naturaleza jurídica de la imputación a parte creditoris. Por una parte, hay quienes sostienen la teoría de que la imputación califica como un negocio bilateral. Por otra parte, se encuentran los autores que sostienen la tesis que ubica la imputación entre los negocios unilaterales (p. 132).

Los que sostienen la teoría del negocio jurídico bilateral equiparan a una verdadera y propia aceptación de la propuesta de imputación formulada por el acreedor el hecho de que el deudor no la rehúse al momento de la recepción del recibo. Este comportamiento omisivo del deudor constituiría una suerte de aceptación idónea para perfeccionar el acuerdo con el acreedor. De parecer diametralmente opuesto es la doctrina más reciente, la cual niega la posibilidad de entender en sentido contractual la aceptación operada por el deudor. Aquel acto tiene carácter preclusivo y le impide al

22 “Lorsque le débiteur de diverses dettes a accepté une quittance par laquelle le créancier a imputé ce qu'il a reçu sur l'une de ces dettes spécialement, le débiteur ne peut plus demander l'imputation sur une dette différente, à moins qu'il n'y ait eu dol ou surprise de la part du créancier". 
deudor rehusar la imputación del acreedor, y no como una aceptación de la propuesta de imputación del acreedor.

Por su parte, Bozzi (2009) subraya que un requisito de eficacia de la imputación por el acreedor es la aceptación por parte del deudor del recibo que la contiene, la cual le impide pretender una imputación distinta. De acuerdo con el autor italiano, la declaración unilateral de imputación con la cual el acreedor ejercita su facultad de elección está insertada en el mismo recibo. La recepción del documento por parte del deudor no presupone un acuerdo sobre la imputación, en cuanto con ella el deudor satisface solamente su interés de obtener la prueba documental del pago efectuado. La prueba de la aceptación de la imputación se deduce, en cambio, de un hecho negativo. Es decir, de la no contestación del deudor, la cual asume el valor de aquiescencia a la elección del acreedor (Bozzi, 2009, p. 178).

En Argentina, también se discute sobre la naturaleza unilateral o bilateral de la imputación por el acreedor. Al respecto, Cazeaux y Trigo (1986) consideran que la imputación por el acreedor, como la imputación por el deudor, constituye un acto unilateral, a cuya decisión debe atenerse el deudor mientras no exceda los límites del legítimo ejercicio de sus derechos (p. 207).

En España, Hernández (1988) niega que la imputación pueda realizarse por determinación unilateral del acreedor. El autor español considera que se trata de un contrato concerniente a la imputación, celebrado sobre la base de la conducta observada por ambas partes: la del acreedor extendiendo el recibo que contenga la imputación y la del deudor aceptando el recibo (p. 314).

Estevill (1986) explica en su comentario al artículo 1172 del Código Civil español ${ }^{23}$ :

Si el deudor aceptase recibo del acreedor, en el que se efectuase la imputación de la prestación realizada, y aquél nada hiciese constar en contra, en el mismo momento de la entrega del documento, y se ausentase del lugar, se operaría un asentimiento por parte del solvens que significaría la satisfacción de la imputación efectuada por el acreedor (por la fuerza de su propio comportamiento) y en con-

23 "Si aceptare del acreedor un recibo en que se hiciese la aplicación del pago, no podrá reclamar contra ésta, a menos que hubiera mediado causa que invalide el contrato". 
secuencia no será revocable el acto de imputar realizado a iniciativa del accipiens y con la aquiescencia del obligado; se habrá producido el efecto extintivo de la obligación. Ello a menos que haya mediado causa que invalide el contrato. (p. 334)

Díez-Picazo (1996), al analizar el segundo párrafo del artículo 1172 del Código Civil español, niega que dicho precepto legal sustituya "el principio general de imputación como facultad del deudor por una subsidiaria imputación que pasa a ser facultad del acreedor". Para el ilustre jurista español, la facultad de imputar continúa siendo facultad del deudor $\mathrm{y}$, en realidad, el precepto solamente establece:

Una imposibilidad de reclamar contra la imputación del acreedor derivada de la aceptación o de la aquiescencia y de los criterios derivados de la buena fe y de la coherencia del comportamiento. La aceptación de que en este precepto se habla, no tiene por qué ser una declaración expresa, ni resultar consignada en el propio recibo. Basta la aquiescencia y no la impugnación inmediata. (Díez-Picazo, 1996, p. 525)

León Barandiarán (1956), comentando el artículo 1265 del Código Civil de 1936, señala que la imputación la hace el acreedor, pero con el asentimiento del deudor, que se manifiesta por la aceptación del recibo en que el acreedor efectúa la imputación. "Así que tal aceptación comporta propiamente un convenio inter partes [...]" (León Barandiarán, 1956, p. 350). Osterling y Castillo (1996) no se manifiestan de manera expresa sobre el tema, pero se entiende que se adhieren a la posición de León Barandiarán (pp. 343-344).

\subsubsection{Límites a la imputación a parte creditoris}

La doctrina y la legislación comparada coinciden en señalar que el acreedor no tiene límites en su derecho a imputar, como ocurre con la imputación del deudor, pero, conforme con el principio de buena fe, tal derecho debe ser ejercido lealmente. En efecto, el deudor tiene la carga de contestar la imputación del acreedor si pretende paralizar su eficacia. El deudor que no rechaza la imputación del acreedor efectuada en el recibo (al momento que se le entrega el mismo) no puede después reclamar contra esta imputación, salvo que haya sido engañado o inducido para aceptar sin oposición la imputación que no le era favorable. 
De acuerdo con la legislación italiana (artículo 1195 del Codice Civile), las causas que impiden la imputación serían el dolo o "sorpresa" por parte del acreedor. El dolo indica el comportamiento fraudulento del acreedor dirigido a engañar al deudor (haciéndole creer que la imputación hecha responde a los criterios legales, que no puede ser contestada por el deudor, etc.), mientras que la sorpresa consiste en que el acreedor se aprovecha de las condiciones personales del deudor para hacer sin oposición una imputación favorable para sí (Iannicelli, 2008, p. 573).

Iannicelli (2008) señala que la referencia del Código Civil italiano al término no técnico sorpresa ha llevado a la doctrina a proponer una interpretación que permita dotarla de operatividad. En tal sentido, el deudor puede impugnar la imputación del acreedor que el propio deudor tornó eficaz al aceptar el recibo solamente en la hipótesis de que la aceptación sea efecto del dolo o la sorpresa (entendidos como el resultado de un comportamiento desleal) de la contraparte. "El elemento sorpresa se identifica en aquel comportamiento dirigido a aprovecharse de las condiciones inherentes a la persona del deudor, induciéndolo a aceptar sin oposición una imputación en realidad no favorable" (Iannicelli, 2008, p. 573).

En síntesis, entonces, el acreedor al ejercer su facultad de imputar debe actuar lealmente con el deudor. Igualmente, el deudor debe impugnar prontamente la imputación fraudulenta hecha en el recibo, so pena de la consolidación creada. En efecto, como bien lo advierte Bozzi (2009) respecto al artículo 1195 del Código Civil italiano (que resulta extensivo al artículo 1258 del Código Civil peruano), la norma no pone un límite temporal para la contestación del deudor; de modo que debe considerarse que ella no debe necesariamente ser manifestada inmediatamente, pero en aplicación del deber general de buena fe la impugnación deberá ser de cualquier manera efectuada prontamente. Es decir, en un lapso de tiempo razonable, teniendo en cuenta las circunstancias del caso particular; pues, de lo contrario, el comportamiento del deudor se configura, como se ha observado, como aquiescencia (p. 179). Una vez que el deudor impugna la imputación del acreedor, podrá imputar el pago de acuerdo con su preferencia, siempre teniendo en consideración los límites antes referidos.

Como se ha visto, la doctrina mayoritaria italiana califica la imputación como un negocio jurídico unilateral, con la consecuente aplicación de la disciplina sobre la incapacidad y sobre los vicios de la voluntad. En este sentido, la doctrina italiana discute si la noción de dolo o de sorpresa son equivalentes a las de dolo o de otros vicios de 
la voluntad que legitiman la pretensión de anulación (anulabilidad) (Bordon, 2009), o bien son entendidas como modalidad de comportamiento contrastante con la obligación de corrección y de leal ejercicio de los derechos, a la cual debe atenerse también el acreedor ( $\mathrm{y}$, por tanto, según esta orientación, la sorpresa consistiría en la reticencia del acreedor que sea consciente de la imputación desventajosa para el deudor); en este caso, el remedio consistiría en la pérdida de efecto del comportamiento incorrecto del acreedor. La doctrina más reciente se inclina por esta última posición (p. 313).

Chessa (1996) considera que la tesis tradicional parece preferible, por dos motivos. En primer lugar, porque la referencia al canon de la corrección adquiere carácter seguramente residual, mientras que la fattispecie en examen, teniendo en cuenta las analogías que la doctrina italiana unánimemente reconoce entre dolo y sorpresa, ha inducido a reconducir a la sorpresa en el ámbito de la específica disciplina prevista para el dolo. En segundo lugar, la equiparación de la sorpresa al dolo, entendido como vicio de la voluntad, se armoniza mejor con una calificación bilateral de la estructura de la imputación a parte creditoris (p. 137).

Por su parte, el artículo 775 del Código Civil argentino (1871) establece:

Cuando el deudor no ha escogido una de las deudas líquidas y vencidas para la imputación del pago, y hubiese aceptado recibo del acreedor, imputando el pago a alguna de ellas especialmente, no puede pedir que se impute en cuenta de otra, a menos que haya mediado dolo, violencia o sorpresa por parte del acreedor.

De acuerdo con Cazeaux y Trigo (1996), la imputación hecha por el acreedor no será válida cuando hubiere "mediado dolo, violencia o sorpresa por parte del acreedor". Para estos autores, el dolo y la violencia son vicios de la voluntad. El dolo es un engaño y la violencia, el temor de sufrir un mal inminente y grave a la persona. La "sorpresa", según los autores argentinos:

Constituye, en cambio, un vicio que no existe con relación a los actos jurídicos en general, lo cual plantea el problema de su caracterización [...]. [Y luego añaden que] la sorpresa sería una suerte de dolo menor, sin la mise-en-scène ni las maniobras engañosas previas, pero que al igual que el dolo importa deslealtad o abuso de confianza por parte del acreedor, consistiendo esencialmente en 
una explotación de la ignorancia o inexperiencia del deudor, aprovechados con toda celeridad, brusca o inopinadamente, por el acreedor, para imponer una imputación que es perjudicial para aquél. (Cazeaux y Trigo, 1996, p. 207)

Más adelante, agregan que si bien el artículo 775 no alude al error como vicio anulatorio de la imputación del pago, ello no importa su exclusión.

El artículo 1172 del Código Civil (1889) español establece: "Si el deudor acepta una imputación hecha por el acreedor en el recibo que éste facilite, el deudor no puede reclamar contra tal imputación a menos que hubiese mediado una causa que invalide el contrato [cursivas añadidas]". La doctrina española discute sobre el alcance de la expresión "causa que invalide el contrato". Para algunos autores, la referencia a causas que invaliden el contrato lleva a la conclusión de que lo que se impugna no es la imputación en sí misma, sino la relación obligatoria de la que el pago deriva. Así, si el contrato del que deriva la relación obligatoria fuera nulo, el deudor puede pretender que el pago hecho sea imputado a otra deuda. Para otros, en cambio, el contrato al que se refiere el artículo 1172 del Código Civil español es el de imputación, que necesariamente debe celebrarse entre el deudor y el acreedor (Díez-Picazo, 1996, p. 525).

En este último sentido, se manifiesta Hernández (1988), quien, como ya se ha adelantado, niega que la imputación pueda realizarse por determinación unilateral del acreedor, pero reconoce que la aceptación por el deudor de un recibo del acreedor en el que este haga la aplicación del pago impide a aquel (el deudor) formular oposición. El autor citado considera que esta modalidad de la imputación se presentará normalmente cuando el deudor, al efectuar el pago, no haya hecho uso de su derecho a imputar, pero admite que es posible que medie el previo ejercicio de tal derecho, en cuyo caso la imputación propuesta por el acreedor en el recibo implicará la modificación de la precedente. Una vez aceptado el recibo por el deudor, este solo puede oponerse por la "invalidez del contrato", y por tal entiende "el que se origina o modifica la imputación, y no aquel o aquellos de donde puedan proceder los créditos objeto de la imputación" (Hernández, 1988, p. 314).

Para Díez-Picazo (1996), "más riguroso parece sostener que la referencia se hace a las genéricas causas de invalidación de los contratos, que aquí resultarían aplicables, no porque haya contrato, sino en virtud de la remisión legal". Teniendo en cuenta que el origen de la norma se 
encuentra en el artículo 1255 del Código Civil francés, la expresión "causa que invalide el contrato" englobaría la totalidad de vicios del consentimiento (p. 525).

(i) Los límites a la imputación a parte creditoris en el Código Civil

Sobre el particular, el artículo 1258 del Código Civil (1984) establece:

Cuando el deudor no ha indicado a cuál de las deudas debe imputarse el pago, pero hubiese aceptado recibo del acreedor aplicándolo a algunas de ellas, no puede reclamar contra esta imputación, a menos que exista causa que impida practicarla [cursivas añadidas].

Para Osterling y Castillo (1996), la expresión "a menos que exista causa que impida practicarla" de la última parte del artículo 1258 del Código Civil (1984) se refiere a los siguientes supuestos:

1. Cuando el acreedor imputa el pago a una obligación ilíquida o no vencida, ya que el deudor, en este caso, todavía no estaría obligado a pagar.

2. Cuando el acreedor imputa el pago a una obligación ya pagada o extinguida, que originaría un caso de pago indebido.

Ambos autores no consideran comprendido dentro de la expresión "a menos que exista causa que impida practicarla" de la última parte del artículo 1258 del Código Civil el supuesto del acreedor que imputa el pago a una obligación ya prescrita:

Caso en el cual el deudor siempre habría estado obligado a pagar la prestación, con la única salvedad de que el acreedor carecía de acción legal para cobrarla. [...] Debemos señalar, en este punto, que si se pagase parte de una deuda prescrita, resulta evidente que al pretender cobrarse el saldo, el deudor podría oponer la excepción de prescripción. (Osterling y Castillo, 1996, p. 345)

Discrepo respetuosamente. Es cierto que la expresión "a menos que exista causa que impida practicarla" del artículo 1258 del Código Civil (1984) es lo suficientemente amplia como para hacer pensar que, en nuestro ordenamiento jurídico, la imputación a parte creditoris tiene límites como en el caso de la imputación del deudor. No obstante, en mi opinión, esa interpretación no es la correcta. 
Osterling (2007), ponente del Libro de Obligaciones, señala que el artículo 1258 del Código Civil tiene origen en el artículo 1265 del Código Civil de 1936. No obstante, en la expresión analizada, este artículo presentaba una frase diferente: "a menos que hubiese causa que invalide el acto", lo que recuerda al Código Civil español (artículo 1172) que señala: "a menos que hubiese mediado una causa que invalide el contrato". Como se ha visto, el artículo 1172 del Código Civil español tiene como fundamento el artículo 1255 del Código Civil francés que dice: "à moins qu'il n'y ait eu dol u surprise de la part du créacier". Por tanto, si se hace una derivación lógica, debería concluirse que si el deudor hubiese aceptado recibo del acreedor aplicándolo a algunas de ellas, no puede reclamar contra esta imputación, a menos que haya mediado dolo o sorpresa por parte del acreedor, lo cual significaría que no existen límites para la imputación a parte creditoris, siempre que haya sido efectuada de buena fe (sin dolo o sin sorpresa) (Osterling, 2007, p. 178).

Pero hay otras razones más concretas para discrepar. Como se ha mencionado, para Osterling y Castillo habría una causa que impida practicar la imputación por el acreedor cuando este "imputa el pago a una obligación ilíquida". Ello no es cierto. Cuando el artículo 1256 del Código Civil (1984) establece que el deudor no puede imputar el pago a una deuda ilíquida, indica claramente "sin el asentimiento del acreedor". Esto significa que es un impedimento favor creditoris. En tal sentido, si es el propio acreedor quien imputa el pago a una deuda ilíquida, no puede afirmarse que exista causa que impida realizarla.

Por otro lado, los autores consideran que habría una causa que impida practicar la imputación por el acreedor cuando este "imputa el pago a una obligación no vencida, ya que el deudor, en este caso, todavía no estaría obligado a pagar". Si se aceptara que existe una limitación, entonces, se debe precisar que lo señalado por los autores nacionales solo sería de aplicación cuando el plazo se establece en beneficio del deudor o en beneficio de ambas partes, pues, en tales supuestos, el plazo suspende la exigibilidad de la prestación. A pesar de ello, no sería aplicable cuando el plazo se establece en beneficio del acreedor, pues, en tal caso, la prestación puede ser exigida por el acreedor antes del vencimiento del plazo. 
En mi opinión, es precisamente en supuestos como estos, cuando el plazo se encuentra establecido en beneficio del deudor o en beneficio de ambas partes, que resulta de aplicación el artículo 1258 del Código Civil. En efecto, cuando el acreedor realiza la imputación y el deudor no la rehúsa, esta conducta del deudor tiene el valor de aquiescencia; es decir, significa que el deudor consiente dicha imputación (en el supuesto analizado, acepta efectuar un pago anticipado). Es la misma razón por la cual el acreedor puede imputar el pago del deudor a una deuda prescrita (Osterling y Castillo, 1996, p. 345).

Cabe reiterar que en supuestos como estos últimos es donde encuentra aplicación el artículo 1258 del Código Civil. Son los casos en los cuales la imputación del acreedor es posible, puesto que existe la aquiescencia del deudor, pues, de lo contrario, no podría imputarse el pago. Así, por ejemplo, si el acreedor puede imputar el pago a una deuda prescrita, es porque el acreedor con la aquiescencia lo permite, renunciando tácitamente a la prescripción (artículo 1991 del Código Civil24). Si el deudor no consintiera (aquiescencia), el acreedor no podría renunciar a la prescripción por el deudor, puesto que la renuncia solo le compete a este.

Osterling y Castillo (1996) afirman que también habría una causa que impida practicar la imputación por el acreedor cuando este "imputa el pago a una obligación ya pagada o extinguida, que originaría una caso de pago indebido". Coincido que en este supuesto existe una causa que impide practicar la imputación, no solo por el acreedor, sino incluso por el deudor, pero considero que este no es el supuesto contemplado en el artículo 1258 del Código Civil.

Como se ha señalado, el acto de imputación determina su efecto -la referencia de la atribución patrimonial a la obligación que va a ser extinguida- según la decisión del autor del acto (el deudor o el acreedor) y, por ello, se afirma que la imputación es un negocio de destinación, pues destina la atribución patrimonial (pago) a una u otra relación obligatoria conforme a la decisión de su autor (deudor o acreedor). En el caso de la imputación a parte creditoris, la decisión

24 "Puede renunciarse expresa o tácitamente a la prescripción ya ganada. Se entiende que hay renuncia tácita cuando resulta de la ejecución de un acto incompatible con la voluntad de favorecerse con la prescripción". 
del acreedor es la que hace la referencia, pero el deudor, al "aceptar" el recibo sin contestar, reconoce la destinación efectuada por el acreedor. Por ello, solo podrá luego reclamar contra tal imputación si hubo un comportamiento desleal del acreedor.

Cuando el acreedor refiere la atribución patrimonial (cuando imputa) a una relación obligatoria inexistente (porque nunca existió o porque ya se había extinguido), la aquiescencia del deudor no salva la situación. Por ende, estamos frente a un pago indebido. En tal sentido, la imputación del acreedor es ineficaz y el deudor puede exigir la restitución de la atribución patrimonial efectuada. La aquiescencia del deudor solo permite presumir su error, de acuerdo con el artículo 1273 del Código Civil ${ }^{25}$. Creo, sin embargo, que el deudor, en lugar de requerir la restitución, podría optar por realizar una imputación de dicha atribución patrimonial, si fuera el caso $^{26}$.

Por lo tanto, reitero que el artículo 1258 del Código Civil (1984) debe ser entendido de la siguiente manera: "Si el deudor hubiese aceptado recibo del acreedor aplicándolo a algunas de ellas, no puede reclamar contra esta imputación, a menos que haya mediado dolo o sorpresa por parte del acreedor".

\subsection{Imputación legal}

A falta de imputación voluntaria, encuentran aplicación los criterios legales de imputación regulados en el artículo 1259 del Código Civil (1984):

No expresándose a qué deuda debe hacerse la imputación, se aplica el pago a la menos garantizada; entre varias deudas igualmente garantizadas, a la más onerosa para el deudor; y entre varias deudas

25 “[...] Sin embargo, se presume que hubo error en el pago cuando se cumple con una prestación que nunca se debió o que ya estaba pagada. Aquel a quien se pide la devolución puede probar que la entrega se efectuó a título de liberalidad o por otra causa justificada".

26 Podría ocurrir que no exista pluralidad de obligaciones que vinculen al mismo acreedor y al mismo deudor, sino solo una respecto a la cual el deudor efectúa el pago. Si en tal situación el acreedor imputa el pago a una relación obligatoria inexistente, entonces, creo que la imputación efectuada por el acreedor carecería de efecto, puesto que no habría existido incertidumbre respecto a qué obligación se refiere el pago del deudor. 
igualmente garantizadas y onerosas, a la más antigua. Si estas reglas no pueden aplicarse, la imputación se hará proporcionalmente.

Cabe señalar que el artículo 1257 del Código Civil también contiene un criterio legal de imputación. El artículo 1259 establece los criterios legales de imputación en el siguiente orden jerárquico:

- $\quad$ El pago se imputa a la deuda menos garantizada.

- $\quad$ Entre varias deudas igualmente garantizadas, el pago es imputado a la más onerosa para el deudor.

- $\quad$ Entre varias deudas igualmente garantizadas y onerosas, el pago es imputado a la más antigua.

- $\quad$ Si estas reglas no pueden aplicarse, la imputación se hará proporcionalmente.

No obstante, debe hacerse una precisión en el orden de aplicación de los criterios legales de imputación:

- A la deuda vencida.

- $\quad$ Entre varias deudas vencidas, a la deuda menos garantizada.

- $\quad$ Entre varias deudas igualmente garantizadas, a la más onerosa para el deudor.

- $\quad$ Entre varias deudas igualmente garantizadas y onerosas, a la más antigua.

- $\quad$ Si estas reglas no pueden aplicarse, la imputación se hará proporcionalmente.

El orden jerárquico de los criterios legales está dirigido a atemperar los intereses de las partes. Los criterios legales son enumerados taxativamente por el legislador y entre ellos existe una precisa jerarquía, de modo que la aplicación de cada uno de ellos se admitirá, en el orden en el cual son enumerados, siempre que falten los presupuestos para recurrir al criterio precedente.

Díez-Picazo (1996), refiriéndose al artículo 1174 del Código Civil español (1889), que establece la imputación legal, señala que se trata de una norma supletoria y, por tanto, nada impide que el negocio jurídico constitutivo de la obligación introduzca criterios de imputación de pagos diferentes de los legales (p. 528). 


\subsubsection{La imputación a la deuda vencida}

Si bien el artículo 1259 del Código Civil (1984) no lo señala, entre varias deudas la imputación deberá hacerse respecto a la vencida. Según Moisset de Espanés (2000), "parece contrario a la lógica que la ley disponga que la imputación del pago, en caso de silencio de las partes, se efectúe a deudas que todavía no son exigibles" (p. 216). Al respecto, el artículo 1193 del Código Civil italiano (1942) establece: "In mancanza di tale dichiarazione, il pagamento deve essere imputato al debito scaduto; tra più debiti scaduti, a quello meno garantito [...]".

En tal sentido:

- Entre una deuda vencida ${ }^{27}$ y una deuda no vencida la prestación debe imputarse a la deuda vencida

De acuerdo con Bianca (1993), este criterio (el de la deuda vencida) prevalece incluso sobre el artículo 1194 del Codice Civile (artículo 1257 del Código Civil peruano), mientras que este prevalece sobre los otros criterios del artículo 1193 del Codice Civile (artículo 1259 del Código Civil peruano):

Suponiendo, por ejemplo, que la deuda del precio haya sido dividida en cuotas, las prestaciones van a extinguir las cuotas por las cuales haya ya vencido el término de pago prescindiendo de la circunstancia que tengan por objeto capital o intereses. (p. 343)

El hecho de que el pago deba imputarse primero a una deuda vencida se justifica para evitar al deudor la responsabilidad por mora y el pago de los intereses moratorios.

- $\quad$ Entre varias deudas vencidas, entonces, se aplicarán los criterios legales de imputación en el orden establecido en el artículo 1259 del Código Civil

Bianca (1993) advierte que el Codice Civile no prevé la hipótesis en la cual ninguna de las deudas fuera "no vencida", pero considera que en tal caso deben aplicarse los criterios legales de imputación señalados en el artículo 1259 del Código Civil peruano (p. 34).

27 Deuda vencida no significa deuda prescrita; cuando se habla de deuda vencida se refiere a aquella prestación respecto de la cual el acreedor puede pretender su ejecución. 
León Barandiarán (1956), comentando el artículo 1267 del Código Civil peruano de 1936 (artículo 1259 del actual), afirmaba que el artículo únicamente hacía referencia a deudas vencidas, concordando con el artículo 1264 (artículo 1256 del Código Civil actual) (p. 356).

\subsubsection{La imputación a la deuda menos garantizada}

Entre varias deudas vencidas, la imputación se hace con referencia a la deuda menos garantizada. Este criterio es a favor del acreedor, que es el único legitimado a alegar la inobservancia (León Barandiarán, 1956, p. 356).

Se refiere a las garantías en sentido técnico-jurídico, es decir, a las garantías reales o personales. En esta línea, normalmente se ha considerado que la mayor o menor garantía de una deuda está en función de la existencia o no de garantías. Así, por ejemplo, entre un crédito quirografario y un crédito sujeto a garantía real o personal: el primero es menos garantizado. Asimismo, entre un crédito garantizado con "garantías personales" y otro con "garantías reales", el primero es menos garantizado.

Osterling y Castillo (1996) no comparten este criterio. Para los autores nacionales, una garantía no es necesariamente mejor o más idónea que otra por ser de naturaleza distinta. En tal sentido, este aspecto es susceptible de generar las mayores controversias y, por tanto, finalmente serán los tribunales los encargados de dilucidar cuál es la obligación más garantizada (pp. 355-356).

La jurisprudencia italiana oscila entre una interpretación restrictiva y una amplia. Así, por un lado, hay sentencias en las cuales se considera que el segundo párrafo del artículo 1193 del Codice Civile (similar a nuestro artículo 1259 del Código Civil) se refiere a garantías en sentido técnico (personales o reales), "y la relativa valorización vaya fijada a su mayor o menor valor jurídico que deriva de la apariencia formal" (Iannicelli, 2008, p. 574; Bozzi, 2009, pp. 140-141). En otras sentencias, en cambio, se ha precisado que la expresión "deuda menos garantizada" debe entenderse no en sentido estrictamente técnico-jurídico, sino como deuda menos tutelada por el derecho en sentido lato; así, por ejemplo, porque su tutela es menos fluida aún en términos procesales, o bien es más costosa. En tal sentido, por ejemplo, en el caso de una relación obligatoria plurisubjetiva, una pluralidad pasiva solidaria sería más garantizada que una parciaria.

Esta última tendencia concede al juez (al árbitro) un campo de discrecionalidad más amplio. Si bien, por un lado, este hecho permite 
alcanzar un resultado más conforme con la justicia; por otro lado, puede generar decisiones discutibles o incertidumbres. No obstante, creo que esta amplitud hace posible superar ciertos problemas que generaría el primer criterio.

En efecto, normalmente se ha considerado que las "garantías reales" resultan más eficientes que las "garantías personales", entre otras cosas, porque la constitución de garantías mediante la afectación de bienes específicos (garantías reales) implica una reducción significativa de los costos de transacción, mientras que las "garantías personales", sin bien mejoran la posición del acreedor en cuanto terceras personas se obligan con el deudor, no reducen los costos de información, sino que, al contrario, se incrementan, pues no solo es necesario obtener información del patrimonio del deudor, sino también de los terceros que garantizan la deuda.

Si bien es cierto que las garantías reales implican un menor costo de información ex ante y un menor costo ex post respecto al control del patrimonio, lo cierto es que los costos de ejecución son extremadamente altos (específicamente en el caso de la ejecución de una hipoteca). En cambio, han aparecido nuevas formas de garantías personales que permiten reducir los costos de información, en la medida en que son otorgadas por entidades de reconocida solvencia y, además, su ejecución es inmediata. Se trata de las garantías autónomas.

El problema es que se suele reconducir estas nuevas garantías al paradigma de las garantías personales: la fianza. Entonces, lo que debe hacerse para salir del entrampamiento es indagar sobre la posibilidad de construir en nuestro derecho el concepto de garantía personal atípi$\mathrm{ca}^{28}$. Este es el caso de la llamada carta fianza. En tal sentido, una deuda garantizada con una carta fianza parece ser más garantizada que una con hipoteca. Una posición distinta es la de Osterling y Castillo (1996), para quienes: “si una obligación está garantizada por una sólida hipoteca y otra por una sólida fianza bancaria, las dos estarían igualmente garantizadas" (p. 355).

28 Por Resolución 50/48 del 26 de enero de 1996, la Asamblea General de las Naciones Unidas aprobó la Convención de las Naciones Unidas sobre Garantías Independientes y Cartas de Créditos Contingentes (en adelante Convención), cuyo proyecto fue elaborado por la Comisión de las Naciones Unidas para el Derecho Mercantil Internacional. Esta Convención no ha sido suscrita por el Perú. 


\subsubsection{La imputación a la deuda más onerosa para el deudor}

Entre deudas igualmente garantizadas, la imputación se hace con referencia a la deuda más onerosa para el deudor; por lo tanto, se manifiesta en un favor frente al deudor, que es liberado del vínculo que más pesa sobre su esfera jurídica. Así, por ejemplo, supongamos que una de las obligaciones del deudor devenga intereses legales y la otra devenga intereses a una tasa más elevada. La segunda deuda es más onerosa para el deudor (Bianca, 1993, p. 344).

Se estima que son más onerosas las que llevan intereses o, entre varias que llevan intereses, las que paguen una tasa más alta; la existencia de cláusulas penales es otro índice de onerosidad ${ }^{29}$ (Moisset de Espanés, 2000, p. 117). Como se ha resuelto por la jurisprudencia argentina, deberá entenderse que una obligación que se encuentra en estado de ser reclamada por vía ejecutiva es más gravosa que aquellas sometidas a la vía ordinaria.

Para Osterling y Castillo (1996), la determinación de la mayor onerosidad de la deuda no tiene precisión absoluta, "pues podría entenderse que el precepto se refiere al porcentaje de intereses que generen las obligaciones o a los montos de las obligaciones principales (capitales adeudados)". En opinión de los autores nacionales, "la obligación más onerosa no sería necesariamente la de mayor monto, pues si una, la de menos cuantía, devenga intereses del $20 \%$ anual, y la otra intereses del $10 \%$ anual, la imputación se hará a la primera" (p. 357).

\subsubsection{La imputación a la deuda más antigua}

Entre varias deudas igualmente onerosas, la imputación se hace respecto a la deuda más antigua. ¿Qué debe entenderse por mayor antigüedad? ¿Debe tomarse en consideración la fecha de nacimiento de la relación obligatoria o la del vencimiento de la obligación?

La doctrina italiana se inclina por considerar la del vencimiento más antiguo (Bianca, 1993, p. 344; Bordon, 2009, p. 304; Bozzi, 2009, p. 176; Chessa, 2008, p. 142; Breccia, 1991, p. 570). Coincido con esta opinión; en consecuencia, entre varias deudas igualmente onerosas, deberá imputarse a la deuda que primero hubiera vencido, y si varias hubieran

29 El Código Civil argentino en el artículo 778 menciona algunas de estas hipótesis, siendo la enumeración meramente ejemplificativa. 
vencido simultáneamente, a la más antigua de nacimiento (artículo 784 del Código Civil portugués) (Moisset de Espanés, 2000, p. 117).

Una posición distinta es la de Osterling y Castillo (1996), quienes señalan: "En resumen, ante la encrucijada de optar definitivamente acerca de cuál de las obligaciones es la que se extingue primero, resulta plenamente razonable que sea aquella que se contrajo primero" (p. 357). Este es el sentido del artículo 6.1.12 de los Principios sobre Contratos Comerciales Internacionales (UNIDROIT, 2010): “(d) La obligación que surgió primero".

\subsubsection{El criterio proporcional}

Si el pago no es imputable con base en los criterios precedentes, se imputa proporcionalmente, según el monto de cada uno. Si el acreedor, por ejemplo, tiene tres créditos que juntos suman 150,00 soles y acepta recibir 75,00 soles, la imputación será por la suma de 25,00 soles (si el monto de los tres créditos era 50 por cada uno) (Breccia, 1991, pp. 570-571).

¿Esta norma supone una excepción a la prohibición del pago parcial? Para Iannicelli (2008, p. 576), el criterio de la proporcionalidad no constituye una excepción a la prohibición del pago parcial (primer párrafo del artículo 1221 del Código Civil); por tanto, el deudor no podría ejecutar un pago por un monto menor de las deudas frente al acreedor, sometiéndose al último inciso del artículo 1193 del Código Civil peruano, en caso de que el acreedor rehúse, legítimamente, a aceptarlo. Para Bozzi (2009), la imputación proporcional constituye un criterio de cierre que deroga la prohibición del pago parcial (artículo 1181 del Codice Civile; artículo 1221 del Código Civil) (p. 176).

Este último criterio de cierre es simplemente lógico, pero contiene un perfil favorable al deudor en cuanto puede prácticamente constreñir al acreedor a aceptar un pago parcial. Di Majo considera que el criterio de la imputación proporcional constituye una derogación de la facultad reconocida al acreedor de rehusar el pago parcial (Chessa, 1996, pp.142-143).

Chessa (1996, p. 143) no comparte esta posición, pues en su opinión la excepción al artículo 1181 del Codice Civile (artículo 1221 del Código Civil peruano, que recoge el principio de indivisibilidad del pago) podría presentarse solo en la hipótesis -no contemplada por el criterio de imputación proporcional- de efectuar un pago inferior también a la deuda menor. Hernández (1988) considera que, al aplicarse la norma subsidiaria de último grado ("el pago se imputará a todas a prorrata"), 
"se introduce una marcada excepción al principio de indivisibilidad del pago. La imputación proporcional de lo pagado implica dar entrada a tantos pagos parciales cuantos sean los créditos pendientes" (p. 316).

\subsubsection{Legislación comparada: órdenes jerárquicos distintos}

Algunos ordenamientos jurídicos tienen un orden jerárquico distinto del adoptado por el Código Civil peruano; así, por ejemplo, el artículo 1174 del Código Civil español ${ }^{30}$, el artículo 778 del Código Civil argentino ${ }^{31}$, el artículo 2093 del Código Civil mexicano ${ }^{32}$ y el artículo 1128 del Código Civil de Puerto Rico ${ }^{33}$. En efecto, en estos Códigos Civiles, entre varias deudas vencidas, se imputará a la más onerosa para el deudor, a diferencia del Código Civil peruano que, siguiendo el orden jerárquico establecido en el Código Civil italiano, primero se imputa a la menos garantizada (favor creditoris) $\mathrm{y}$, entre deudas igualmente garantizadas, la imputación se hace con referencia a la deuda más onerosa para el deudor (favor debitoris).

Así, por ejemplo, entre una deuda quirografaria con bajos intereses y otra garantizada con hipoteca con altos intereses, de acuerdo con el Código Civil peruano (1984), se imputaría a la quirografaria, que es la menos garantizada para el acreedor, a pesar de que la deuda garantizada con hipoteca es más onerosa para el deudor.

Finalmente, resulta interesante citar el artículo 489 del Código Civil japonés (1898) que establece lo siguiente:

30 “Cuando no pueda imputarse el pago según las reglas anteriores, se estimará satisfecha la deuda más onerosa al deudor entre las que estén vencidas. Si éstas fueren de igual naturaleza y gravamen, el pago se imputará a todas a prorrata".

31 "No expresándose en el recibo del acreedor a qué deuda se hubiese hecho la imputación del pago, debe imputarse, entre las de plazo vencido, a la más onerosa al deudor, o porque llevara intereses, o porque hubiera pena constituida por falta de cumplimiento de la obligación, o por mediar prenda o hipoteca, o por otra razón semejante. Si las deudas fuesen de igual naturaleza, se imputará a todas a prorrata".

32 "Si el deudor no hiciere la referida declaración, se entenderá hecho el pago por cuenta de la deuda que le fuere más onerosa entre las vencidas. En igualdad de circunstancias, se aplicará a la más antigua, y siendo todas de la misma fecha, se distribuirá entre todas ellas a prorrata".

33 "Cuando no pueda imputarse el pago según las reglas anteriores, se estimará satisfecha la deuda más onerosa al deudor entre las que estén vencidas. Si éstas fueren de igual naturaleza y gravamen, el pago se imputará a todas a prorrata". 
Si las partes no acordaron ninguna determinación sobre la imputación del pago, se procederá de la siguiente manera:

Si hubiese obligaciones vencidas y otras que todavía no lo estuvieren, se imputará el pago a las primeras;

Si todas las obligaciones hubieren vencido o ninguna de ellas hubiere vencido, se estimará satisfecha la deuda cuyo pago sea más provechoso para el deudor;

Si todas las deudas resultaren igual de gravosas, se imputará el pago a las que hayan vencido o vencieren con anterioridad;

Si, según las reglas de los números anteriores, todas las deudas fueran de igual naturaleza y gravamen, el pago se imputará a todas a prorrata.

\section{Referencias}

BGB. Código Civil (Alemania). (1 de enero de 1900). Recuperado de http://www.gesetze-im-internet.de/englisch_bgb/

Bianca, M. (1993). Diritto civile (tomo 4). Milán, Italia: Giuffrè.

Bordon, R. (2009). Commentario al articolo 1193 del Codice Civile. En Commentario al Codice Civile. Artt. 1173-1320. Obbligazioni. A cura di Paolo Cendon. Milán, Italia: Giuffrè.

Bozzi, G. (2009). Comportamento del debitore e attuazione del rapporto obbligatorio. En Diritto civile (volumen III: Obbligazioni. I Il Rapporto Obbligatorio). Milán, Italia: Giuffrè.

Breccia, U. (1991). Le obbligazioni. En Trattato di diritto privato. A cura di Giovanni Iudica e Paolo Zatti. Milán, Italia: Giuffrè.

Cárdenas Quirós, C. (1993). Intereses legales e indemnización de daños (acerca del segundo párrafo del artículo 1985 del Código Civil). Ius et Veritas, 5(8), 21-24.

Caringella, F., y De Marzo, G. (2008). Manuale di diritto civile (volumen II: Le obligazioni). Milán, Italia: Giuffrè.

Cazeaux, P. N., y Trigo, F. A. (1986). Compendio de derecho de las obligaciones (tomo 2). La Plata, Argentina: Librería Editora Platense.

Chessa, C. (1996). L'adempimento. Milán, Italia: Giuffrè.

Código Civil (Italia). Decreto Real 262. (4 de abril de 1942). Recuperado de http://www.jus.unitn.it/cardozo/obiter_dictum/codciv/Codciv.htm 
Código Civil (Perú). Decreto legislativo 295. (25 de julio de 1984). Recuperado de http://spij.minjus.gob.pe/CLP/contenidos.dll?f=templa tes\&fn=default-codcivil.htm\&vid=Ciclope:CLPdemo

Código Civil (Francia). Loi contenant la réunion des lois civiles en un seul corps de lois. (21 de marzo de 1804). Madrid, España: Marcial Pons, Ediciones Jurídicas y Sociales.

Código Civil (Uruguay). Ley 16.603. (19 de octubre de 1995). Montevideo, Uruguay: Fundación de Cultura Universitaria.

Código Civil (Portugal). Decreto Ley 47344. (25 de noviembre de 1966). Recuperado de http://www.pgdlisboa.pt/leis/lei_mostra_articulado.php?nid=2424\&tabela=leis\&ficha=1\&pagina=1\&so_miolo=

Código Civil (España). Ley de 26 de mayo de 1889. (29 de julio de 1889). Recuperado de http://civil.udg.es/normacivil/estatal/cc/indexcc.htm

Código Civil (Argentina). Ley 340. (1 de enero de 1871). Buenos Aires, Argentina: La Ley.

Código Civil Federal (México). (1 de octubre de 1932). Recuperado de http://www.diputados.gob.mx/LeyesBiblio/pdf/2_241213.pdf

Código Civil (Japón). Ley 89/1896 y 9/1898. (16 de julio de 1898). Navarra, España: Arrazadi.

Díez-Picazo, L. (1996). Fundamentos del derecho civil patrimonial (volumen II, 5. ${ }^{a}$ ed.). Madrid, España: Civitas.

Estevill, L. P. (1986). El pago. Barcelona, España: Bosch.

Gomes, O. (1986). Obrigações (8. ${ }^{a}$ ed.). Río de Janeiro, Brasil: Forense.

Guzmán Ferrer, F. (1982). Código Civil (tomo 4). Lima, Perú: Cultural Cusco.

Hernández, A. (1988). Obras completas. Derecho de obligaciones (tomo 3). Madrid, España: Espasa Calpe.

Iannicelli, S. (2008). Il del pagamento, quietanza, imputazione. En Le obbligazioni. Diritto sostanziale e processuale (tomo I). Milán, Italia: Giuffrè.

International Institute for the Unification of Private Law (UNIDROIT). (2010). Principios UNID ROIT sobre los Contratos Comerciales Internacionales. Recuperado de www.unidroit.org/spanish/principles /.../blackletter2010-spanish.pdf

León Barandiarán, J. (1956). Comentarios al Código Civil peruano (tomo II). Buenos Aires, Argentina: Ediar Editores. 
Mariconde, O. (1977). El régimen jurídico de los intereses. Buenos Aires, Argentina: Lerner Editores.

Moisset de Espanés, L. (2000). Imputación del pago en el Código Civil peruano de 1984. Revista de Derecho Privado 84(2), 133-138.

Osterling, F. (2007). Las Obligaciones (8. a ed.). Lima, Perú: Grijley.

Osterling, F., y Castillo, M. (1996). Tratado de las Obligaciones. En Biblioteca para leer el Código Civil (volumen XVI, primera parte, tomos IV y VII). Lima, Perú: Pontificia Universidad Católica del Perú, Fondo Editorial.

Pothier, R. J. (2007). Tratado de las Obligaciones. Buenos Aires, Argentina: Heliasta.

Vidal Ramírez, F. (1990). La capitalización de intereses. En Tendencias actuales y perspectivas del derecho privado y el sistema jurídico latinoamericano. Lima, Perú: Cultural Cusco. 
